\title{
18 Different Radiologic Patterns in AIDS at a Glance
}

\author{
JaCques W. A. J. Reeders and Phillip C. Goodman
}

\section{CONTENTS}

18.1 Central Nervous System 293

18.2 Spine and Spinal Cord 300

18.3 Cardiovascular System 302

18.4 Respiratory System 303

18.5 Luminal Gastrointestinal Tract 308

18.6 Liver/Spleen/Biliary Tract 312
18.7 Retroperitoneum 314

18.8 Musculoskeletal system 316

18.9 Different Radiologic Patterns

on Chest Radiographs in AIDS 319

18.10 Pathogens and Neoplasms in AIDS:

Cytologic Methods 322

\subsection{Central Nervous System}

\begin{tabular}{|c|c|c|c|c|}
\hline $\begin{array}{l}\text { Organism/ } \\
\text { disease }\end{array}$ & $\begin{array}{l}\text { Organ } \\
\text { involved }\end{array}$ & Radiologic abnormality & Extent of disease & $\begin{array}{l}\text { Differential } \\
\text { diagnosis }\end{array}$ \\
\hline $\begin{array}{l}\text { Toxo- } \\
\text { plasmosis } \\
\text { (Toxoplasma } \\
\text { gondii) }\end{array}$ & CNS & $\begin{array}{l}\text { Encephalitis/leptomeningitis } \\
\text { CT: } \\
\text { Iso/hypodense ( } 82 \% \text { ) lesions with surrounding } \\
\text { edema and mass effect; contrast enhancement; } \\
\text { well-defined, annular, nodular (rare), sub- } \\
\text { ependymal (rare) lesions; calcifications } \\
\text { MR: } \\
\text { Increased signal foci on long TR images with } \\
\text { iso/hypointense centers. } \\
\text { Short TR images: } \\
\text { Hypointense/contrast enhancement }\end{array}$ & $\begin{array}{l}\text { - Cerebral hemispheres } \\
\text { more frequently affect- } \\
\text { ed than cerebellum/ } \\
\text { brainstem } \\
\text { - Corticomedullary junc- } \\
\text { tion } \\
\text { - Basal ganglia } \\
\text { Other organs involved: } \\
\text { - Lymph nodes } \\
\text { - GI tract } \\
\text { - Respiratory tract }\end{array}$ & $\begin{array}{l}\text { AIDS-related } \\
\text { lymphoma }\end{array}$ \\
\hline
\end{tabular}

J.W.A.J. ReEDERS, MD, PhD

Consultant Radiologist, Department of Radiology, St. Elisabeth Hospital Willemstad, Breedestraat 193(O), Curaçao, Netherlands Antilles

P.C. Goodman, MD

Department of Radiology, Duke University Medical Center, P.O. Box 3808, Durham, NC 22710, USA 


\begin{tabular}{|c|c|c|c|c|}
\hline $\begin{array}{l}\text { Organism/ } \\
\text { disease }\end{array}$ & $\begin{array}{l}\text { Organ } \\
\text { involved }\end{array}$ & Radiologic abnormality & Extent of disease & $\begin{array}{l}\text { Differential } \\
\text { diagnosis }\end{array}$ \\
\hline $\begin{array}{l}\text { AIDS- } \\
\text { related } \\
\text { lymphoma }\end{array}$ & $\mathrm{CN}$ & $\begin{array}{l}\text { (DDD) CT: } \\
\text { Multiple solid iso- or hypodense masses (less } \\
\text { common), hyperdense heterogeneous enhance- } \\
\text { ment ( } 80 \%) \text {; peripheral enhancement due to } \\
\text { central necrosis; round, oval, nodular lesions } \\
\text { with ringlike enhancement. Linear/nodular } \\
\text { subpial and subependymal enhancement } \\
\text { MR: } \\
\text { Hypointense on T1WI; isointense less common; } \\
\text { after contrast center remains hypointense; } \\
\text { margins enhance in smooth/ringlike appearance. } \\
\text { T2WI: variable appearances: increased, } \\
\text { isointense or decreased signal intensity to paren- } \\
\text { chyma. If there is menigeal involvement, this is } \\
\text { better visualized on contrast MR than on contrast } \\
\text { CT } \\
\text { FDG-PET imaging: } \\
\text { uptake by tumor } \\
\text { Thallium-201 (Tl-201) brain SPECT: } \\
\text { uptake by tumor (not by infection) } \\
\text { MR spectroscopy: } \\
\text { mild to moderate increase in lactate and lipids: } \\
\text { markedly evelated choline peak }\end{array}$ & $\begin{array}{l}\text { (Multi)focal lesions: } \\
\text { - Basal ganglia } \\
\text { - Corpus callosum } \\
\text { - Cerebellar vermis } \\
\text { - Hemispheric white } \\
\text { matter } \\
\text { - Periventricular/sub- } \\
\text { ependymal } \\
\text { Other organs involved: } \\
\text { - GI tract } \\
\text { - Bone marrow }\end{array}$ & Toxoplasmosis \\
\hline $\begin{array}{l}\text { Crypto- } \\
\text { coccosis } \\
\text { (Crypto- } \\
\text { coccus } \\
\text { neoformans) }\end{array}$ & CNS & $\begin{array}{l}\text { CT: } \\
\text { Spherical, well-defined iso/hypodense lesion(s); } \\
\text { cryptococcoma, gelatinous pseudocysts } \\
\text { MR: } \\
\text { High signal on long TR images; decreased signal } \\
\text { on short TR images; perivascular space dilatation }\end{array}$ & $\begin{array}{l}\text { - Meninges } \\
\text { - Basal ganglia } \\
\text { - Thalami } \\
\text { - Midbrain } \\
\text { - Corpus callosum } \\
\text { - Cerebral cortex } \\
\text { - Posterior fossa } \\
\text { Other organs involved: } \\
\text { - Respiratory tract } \\
\text { - Lymph nodes } \\
\text { - Liver/spleen } \\
\text { - Bone marrow }\end{array}$ & $\begin{array}{l}\text { Other lesions with } \\
\text { CNS mass effect }\end{array}$ \\
\hline
\end{tabular}




\begin{tabular}{|c|c|c|c|c|}
\hline $\begin{array}{l}\text { Organism/ } \\
\text { disease }\end{array}$ & $\begin{array}{l}\text { Organ } \\
\text { involved }\end{array}$ & Radiologic abnormality & Extent of disease & $\begin{array}{l}\text { Differential } \\
\text { diagnosis }\end{array}$ \\
\hline $\begin{array}{l}\text { Herpes } \\
\text { [herpes } \\
\text { simplex } \\
\text { virus (HSV-1 } \\
\text { and HSV-2)] }\end{array}$ & CNS & $\begin{array}{l}\text { CT: } \\
\text { Necrotizing encephalitis; ventriculitis; } \\
\text { necrotizing vasculitis of entire cord/spinal roots; } \\
\text { generalized swelling, abnormal density or signal } \\
\text { changes in white matter; cortical enhancement } \\
\text { (rare) } \\
\text { MR: } \\
\text { Low signal intensity on T1WI, hyperintensity on } \\
\text { T2WI. Hemorrhage can be seen (foci of increased } \\
\text { signal intensity on T1WI) } \\
\text { SPECT imaging: } \\
\text { Increased perfusion of involved brain areas, even } \\
\text { when CT and MR are negative }\end{array}$ & $\begin{array}{l}\text { Diffuse involvement } \\
\text { - Frontal/temporal lobes } \\
\text { - Brainstem } \\
\text { - Cerebellum } \\
\text { Other organs involved } \\
\text { (mucocutaneous): } \\
\text { - Perianal region } \\
\text { - Oropharynx } \\
\text { - Esophagus }\end{array}$ & $\begin{array}{l}\text { Cytomegalovirus } \\
\text { (CMV) }\end{array}$ \\
\hline $\begin{array}{l}\text { Mycobacteria } \\
\text { [Myco- } \\
\text { bacterium } \\
\text { tuberculosis, } \\
\text { M. avium } \\
\text { intracellulare] }\end{array}$ & CNS & $\begin{array}{l}\text { CT/MR: } \\
\text { Leptomeningitis; meningeal enhancement of the } \\
\text { basal cisterns; granulomata, abscess, calcifica- } \\
\text { tions. Infarction and hydrocephalus, usually the } \\
\text { communicating type. Parenchymal involvement } \\
\text { (less common): ringlike, nodular lesions } \\
\text { Tuberculomas: } \\
\text { CT: } \\
\text { Ring-enhancing lesions due to central necrosis } \\
\text { ("target sign"); central calcifications or punctate } \\
\text { enhancement, surrounded by a rim of hypoden- } \\
\text { sity and a rim of enhancement } \\
\text { MR: } \\
\text { Granulomas are isointense on T1WI with a } \\
\text { slightly hyperintense rim. } \\
\text { Variable signal on T2WI. Usually mass effect and } \\
\text { edema surrounding the tuberculoma } \\
\text { MR with contrast: } \\
\text { Intense nodular and/or ringlike enhancement }\end{array}$ & $\begin{array}{l}\text { Solitary/multiple } \\
\text { Other organs involved: } \\
\text { - Lymph nodes } \\
\text { - Liver/spleen } \\
\text { - Peritoneum } \\
\text { - Bone marrow } \\
\text { - GI tract } \\
\text { - Respiratory tract } \\
\text { - GU tract } \\
\text { - Skin (rare) } \\
\text { - CVS (rare) } \\
\text { - Subarachnoid space } \\
\text { - Subdural/epidural } \\
\text { space } \\
\text { - Corticomedullary junc- } \\
\text { tion } \\
\text { - Periventricular region } \\
\text { - At the side of the per- } \\
\text { forating end-arteries at } \\
\text { the base of the brain }\end{array}$ & $\begin{array}{l}\text { - Toxoplasmosis } \\
\text { - AIDS-related } \\
\text { lymphoma } \\
\text { - Cryptococcosis }\end{array}$ \\
\hline & & $\begin{array}{l}\text { TB abscess } \\
C T \text { : } \\
\text { Hypodense lesion with edema and mass effect; } \\
\text { uniform, mostly thin ring enhancement; may } \\
\text { occasionally be thick and irregular } \\
\text { MR: } \\
\text { Central pus region and liquefactive necrosis is } \\
\text { bright on T2WI; the rim of inflammation is } \\
\text { usually iso- to hypointense on T2WI; rim } \\
\text { enhancement on TWI after contrast }\end{array}$ & Mostly solitary & Bacterial \\
\hline $\begin{array}{l}\text { Varicella } \\
\text { zoster virus }\end{array}$ & CNS & $\begin{array}{l}\text { Encephalitis, neuritis, myelitis, herpes } \\
\text { ophthalmicus } \\
C T \text { may be negative while } \\
\text { MR may reveal signal abnormalities within } \\
\text { brainstem and/or cortical gray matter }\end{array}$ & $\begin{array}{l}\text { Diffuse } \\
\text { - Ganglia of cranial } \\
\text { nerves (V, VII) }\end{array}$ & $\begin{array}{l}\cdot \text { CMV } \\
\text { - Herpes }\end{array}$ \\
\hline
\end{tabular}




\begin{tabular}{lllll}
\hline $\begin{array}{l}\text { Organism/ } \\
\text { disease }\end{array}$ & $\begin{array}{l}\text { Organ } \\
\text { involved }\end{array}$ & Radiologic abnormality & Extent of disease & $\begin{array}{l}\text { Differential } \\
\text { diagnosis }\end{array}$ \\
\hline Brain atrophy & CNS & $\begin{array}{l}\text { CT/MR: } \\
\text { cortical atrophy; widened sulci }\end{array}$ & $\begin{array}{l}\text { Generalized } \\
\cdot \text { Supratentorial }(100 \%)\end{array}$ & - \\
& & - Infratentorial $(70 \%)$
\end{tabular}

\begin{tabular}{|c|c|c|c|c|}
\hline $\begin{array}{l}\text { Progressive } \\
\text { multifocal } \\
\text { leuken- } \\
\text { cephalopathy } \\
\text { Papovavirus } \\
\text { (JC virus) }\end{array}$ & CNS & $\begin{array}{l}\text { CT: } \\
\text { Focal white matter hypodensity without mass } \\
\text { effect, usually without enhancement (demyelina- } \\
\text { tion); patchy enhancement on occasion } \\
\text { MR: } \\
\text { (More sensitive than CT) T1WI: lesions are } \\
\text { hypointense to the parenchyma, sharply } \\
\text { circumscribed } \\
\text { Demyelination: } \\
\text { Zones of increased signal on long TR images; } \\
\text { decreased signal on short TR images. Lesions } \\
\text { against corticomedullary junction, in (deep) } \\
\text { gray matter. } \\
\text { T2WI: hyperintense signal intensity in periven- } \\
\text { tricular and/or subcortical white matter; lesions: } \\
\text { small, but progress to larger areas of involve- } \\
\text { ment. Can be unilateral. No mass effect; rarely } \\
\text { enhancement. If enhancement is present: faint } \\
\text { and peripheral } \\
\text { MR spectroscopy: } \\
\text { Decreased NAA and Cr, increased CHO }\end{array}$ & $\begin{array}{l}\text { - Asymmetric/multifo- } \\
\text { cal bilateral } \\
\text { - Frontal, parietal, occip- } \\
\text { ital region most com- } \\
\text { monly affected } \\
\text { - Corticomedullary junc- } \\
\text { tion. } \\
\text { - Periventricular subcor- } \\
\text { tical } \\
\text { - Posterior fossa (com- } \\
\text { mon) } \\
\text { - Cervical cord (uncom- } \\
\text { mon) } \\
\text { Other organs involved: } \\
\text { - Kidneys }\end{array}$ & $\begin{array}{l}\text { - HIV encephalitis } \\
\text { - HIV demyelina- } \\
\text { tion }\end{array}$ \\
\hline $\begin{array}{l}\text { Focal white } \\
\text { matter } \\
\text { hyper- } \\
\text { intensities }\end{array}$ & CNS & $\begin{array}{l}\text { MR: } \\
\text { T1WI/T2WI: } \\
\text { zones of perivascular demyelination or dilated } \\
\text { perivascular spaces secondary to atrophy: white } \\
\text { matter hyperintensity }\end{array}$ & -Perivascular spaces & - \\
\hline $\begin{array}{l}\text { AIDS-demen- } \\
\text { tia complex }\end{array}$ & CNS & $\begin{array}{l}\text { CT/MR: } \\
\text { Abnormal in } 50 \% \text { : atrophy/white matter disease } \\
\text { Iodine-123 IMP SPECT: } \\
\text { Multiple focal cortical perfusion abnormalities } \\
\text { to be present prior to any evidence of disease on } \\
\text { CT/MR } \\
\text { Tc-99m HMPAO: } \\
\text { Regional abnormalities of cerebral blood flow } \\
\text { FDG-PET: } \\
\text { Alternations/decrease in cerebral (subcortical) } \\
\text { glucose metabolism }\end{array}$ & $\begin{array}{l}\text { Patchy, diffuse, } \\
\text { confluent and } \\
\text { homogeneous }\end{array}$ & - \\
\hline
\end{tabular}




\begin{tabular}{|c|c|c|c|c|}
\hline $\begin{array}{l}\text { Organism/ } \\
\text { disease }\end{array}$ & $\begin{array}{l}\text { Organ } \\
\text { involved }\end{array}$ & Radiologic abnormality & Extent of disease & $\begin{array}{l}\text { Differential } \\
\text { diagnosis }\end{array}$ \\
\hline $\begin{array}{l}\text { Pediatric HIV } \\
\text { infections: } \\
\text { HIV 1-asso- } \\
\text { ciated pro- } \\
\text { gressive en- } \\
\text { cephalopathy }\end{array}$ & CNS & $\begin{array}{l}\text { CT/MR: } \\
\text { - Progressive atrophy and ventricular enlarge- } \\
\text { ment due to myelin loss or reduced myelin. } \\
\text { - White matter hypodensity (infrequent) } \\
\text { - Often calcifications in basal ganglia } \\
\text { (hypointense on MR), bilaterally or in white } \\
\text { matter of frontal lobe } \\
\text { - Enhancement within basal ganglia } \\
\text { T2WI: hyperintensity in basal ganglia, while CT } \\
\text { may be negative } \\
\text { FDG-PET: } \\
\text { Diffuse or focal hypometabolism with sub- } \\
\text { cortical hypermetabolism } \\
\text { MR spectroscopy: } \\
\text { Decreased NAA/Cr ratios in subcortical } \\
\text { structures }\end{array}$ & $\begin{array}{l}\text { Patchy, confluent, } \\
\text { bilateral }\end{array}$ & $\begin{array}{l}\text { Subacute } \\
\text { encephalitis }\end{array}$ \\
\hline
\end{tabular}

\begin{tabular}{|c|c|c|c|c|}
\hline $\begin{array}{l}\text { Pediatric } \\
\text { cerebrovascu- } \\
\text { lar disease }\end{array}$ & CNS & $\begin{array}{l}\text { HIV-related arteriopathy: } \\
\text { CT/MR: } \\
\text { - Fusiform dilatation of circle of Willis (arteri- } \\
\text { omegaly) } \\
\text { - Ischemia or hemorrhage may be found on con- } \\
\text { trast CT or as signal voids on T2WI }\end{array}$ & - & - \\
\hline $\begin{array}{l}\text { Fibrosing } \\
\text { sclerosis }\end{array}$ & CNS & $\begin{array}{l}\text { CT/MR: } \\
\text { Ischemic infarction } \\
\text { MR angiography: } \\
\text { focal areas of vascular stenosis or occlusion }\end{array}$ & $\begin{array}{l}\text { - Basal ganglia } \\
\text { - Frontal lobes }\end{array}$ & - \\
\hline $\begin{array}{l}\text { HIV } \\
\text { (subacute) } \\
\text { encephalitis }\end{array}$ & CNS & $\begin{array}{l}\text { Nonspecific atrophy with deep white matter } \\
\text { changes, without mass effect; microglial nodules } \\
\text { undetectable by CT, but rarely seen on MR } \\
\text { CT: } \\
\text { Areas of low attenuation } \\
\text { MR: } \\
\text { - High signal intensity on long TR images } \\
\text { - Combined lobal atrophy } \\
\text { - Diffuse symmetrical white matter hyper- } \\
\text { intensity on T2WI }\end{array}$ & $\begin{array}{l}\text { Diffuse, symmetrical } \\
\text { - Periventricular } \\
\text { - Basal ganglia } \\
\text { - Cortex }\end{array}$ & PML \\
\hline $\begin{array}{l}\text { Acute } \\
\text { encephalitis } \\
\text { Acute/chronic } \\
\text { meningitis }\end{array}$ & CNS & $\begin{array}{l}\text { Imaging studies are usually negative; atrophy; } \\
\text { white matter lesions less frequently seen on CT; } \\
\text { can be seen on serial MR studies. }\end{array}$ & & \\
\hline
\end{tabular}




\begin{tabular}{|c|c|c|c|c|}
\hline $\begin{array}{l}\text { Organism/ } \\
\text { disease }\end{array}$ & $\begin{array}{l}\text { Organ } \\
\text { involved }\end{array}$ & Radiologic abnormality & Extent of disease & $\begin{array}{l}\text { Differential } \\
\text { diagnosis }\end{array}$ \\
\hline $\begin{array}{l}\text { Cytomegalo- } \\
\text { virus } \\
\text { meningoen- } \\
\text { cephalitis }\end{array}$ & CNS & $\begin{array}{l}\text { Calcifications in neonates; microglial nodules } \\
\text { predominantly in cortex } \\
\text { CT: } \\
\text { Atrophy: often insensitive! usually normal } \\
\text { - White matter hypodensity } \\
\text { - Smooth periventricular/subependymal en- } \\
\text { hancement } \\
\text { MR: } \\
\text { - Ventriculoependymitis; } \\
\text { - T2WI: increased signal changes in peri- } \\
\text { ventricular white matter } \\
\text { Fat-suppressed MR + Gd-DTPA: } \\
\text { - Thickened and enhancing choroid/retina } \\
\text { (CMV retinitis) } \\
\text { - less often: subependymal enhancement }\end{array}$ & $\begin{array}{l}\text { Other organs involved: } \\
\text { - Respiratory system } \\
\text { - Adrenals } \\
\text { - GI tract } \\
\text { - GU tract } \\
\text { - Retina } \\
\text { - Biliary tract } \\
\text { - Liver/gallbladder } \\
\text { - Hematopoietic system }\end{array}$ & $\begin{array}{l}\text { AIDS-related } \\
\text { lymphoma }\end{array}$ \\
\hline $\begin{array}{l}\text { (Acute) } \\
\text { syphilitic } \\
\text { meningitis }\end{array}$ & CNS & $\begin{array}{l}\text { Meningovascular neurosyphilis } \\
\text { CT: } \\
\text { Often unremarkable } \\
\text { - Cerebral atrophy } \\
\text { - Small infarcts due to vasculitis } \\
\text { MR: } \\
\text { T2WI: ischemic injuries are bright } \\
\text { - Post Gd-DTPA: enhancement in region of sub- } \\
\text { acute infarction } \\
\text { - Meningeal enhancement may be present } \\
\text { MR angiography: } \\
\text { Vascular occlusion/narrowing on imaging } \\
\text { studies. Gummas appear as mass lesions at the } \\
\text { brain surface with nodular/ring enhancement, } \\
\text { usually adjacent meningeal enhancement } \\
\text { (varogenic edema) }\end{array}$ & - & - \\
\hline $\begin{array}{l}\text { Nocardiosis } \\
\text { (Nocardia } \\
\text { asteroides; } \\
\text { Nocardia } \\
\text { brasiliensis) }\end{array}$ & CNS & $\begin{array}{l}\text { Hematogenous spread from pulmonary infection } \\
\text { Chest radiograph: } \\
\text { Cavitary lung infiltrates are common } \\
\text { CT: } \\
\text { Multiple brain abscesses: ring-enhancing lesions, } \\
\text { which may be multiple or multiloculated. } \\
\text { Meningitis: less common } \\
\text { MR: } \\
\text { Abscess: } \\
\text { T1WI: central low signal intensity; } \\
\text { T2WI: high signal intensity with a surrounding } \\
\text { capsula; extensive edema/mass effect }\end{array}$ & $\begin{array}{l}\text { Multiple/ } \\
\text { multiloculated }\end{array}$ & $\begin{array}{l}\text { Other fungal } \\
\text { infections: crypto- } \\
\text { coccosis, histoplas- } \\
\text { mosis, coccidioido- } \\
\text { mycosis, blastomy- } \\
\text { cosis }\end{array}$ \\
\hline
\end{tabular}




\begin{tabular}{|c|c|c|c|c|}
\hline $\begin{array}{l}\text { Organism/ } \\
\text { disease }\end{array}$ & $\begin{array}{l}\text { Organ } \\
\text { involved }\end{array}$ & Radiologic abnormality & Extent of disease & $\begin{array}{l}\text { Differential } \\
\text { diagnosis }\end{array}$ \\
\hline $\begin{array}{l}\text { Bacillary } \\
\text { angiomatosis } \\
\text { (Bartonella } \\
\text { henselae; } \\
\text { Bartonella } \\
\text { quintana) }\end{array}$ & CNS & $\begin{array}{l}C T / M R \text { : } \\
\text { Intracerebral enhancing lesions, resembling } \\
\text { Kaposi's sarcoma }\end{array}$ & $\begin{array}{l}\text { Other organs involved: } \\
\text { - Liver, spleen } \\
\text { - Coniunctivae } \\
\text { - Lymph nodes } \\
\text { - Respiratory tract } \\
\text { - Skeletal system: } \\
\text { Lytic bone lesions in } \\
\text { multiple locations }\end{array}$ & Kaposi's sarcoma \\
\hline $\begin{array}{l}\text { Fungal } \\
\text { disease }\end{array}$ & CNS & $\begin{array}{l}\text { - Acute/chronic leptomeningitis/granuloma or } \\
\text { abscess } \\
\text { - Subacute basilar granulomatous meningitis } \\
\text { - Cryptococcomas } \\
\text { CT: } \\
\text { Often unremarkable } \\
\text { - Atrophy } \\
\text { - Communicating hydrocephalus } \\
\text { MR: } \\
\text { May be negative } \\
\text { - Menigeal enhancement on postgadolineum im- } \\
\text { ages } \\
\text { a) Parenchymal mass lesions (cryptococcomas) } \\
\text { b) Dilated Virchow-Robin spaces } \\
\text { c) Parenchymal/leptomeningeal nodules } \\
\text { d) Mixed pattern } \\
\text { CT: } \\
\text { - Hypodense lesions with solid or ring enhance- } \\
\text { ment } \\
\text { - Peripheral small enhancing nodules (granulo- } \\
\text { mas) with punctate calcifications } \\
\text { - Small hypodensities without enhancement in } \\
\text { basal ganglia } \\
\text { - Cysts in basal ganglia ("gelatinous } \\
\text { pseudocysts") }\end{array}$ & $\begin{array}{l}\text { - Virchow-Robin spaces } \\
\text { in midbrain/basal } \\
\text { ganglia } \\
\text { - Leptomeninges }\end{array}$ & $\begin{array}{l}\text { - Cryptococcosis } \\
\text { - Histoplamosis } \\
\text { - Coccidioido- } \\
\text { mycosis } \\
\text { - Blastomycosis }\end{array}$ \\
\hline $\begin{array}{l}\text { Mucor- } \\
\text { mycosis }\end{array}$ & CNS & Intracranial abscess and/or infarction & $\begin{array}{l}\text { Other organs involved: } \\
\text { - Paranasal sinuses }\end{array}$ & \\
\hline Aspergillosis & CNS & $\begin{array}{l}\text { - Vascular occlusion; hemorrhagic infarction } \\
\text { - Focal cerebritis and abscess formation } \\
\text { - Hypointense signal on TIWI and T2WI in the } \\
\text { paranasal sinuses }\end{array}$ & Focal & $\begin{array}{l}\text { Other fungal } \\
\text { infections }\end{array}$ \\
\hline $\begin{array}{l}\text { Candida albi- } \\
\text { cans }\end{array}$ & CNS & $\begin{array}{l}\text { Meningitis, meningoencephalitis, (micro)ab- } \\
\text { scess, granulomata } \\
\text { CT: } \\
\text { Granulomas: } \\
\text { hyperdense nodules with surrounding edema } \\
\text { and nodular ring enhancement; iso/hypodense } \\
\text { lesions with multiple punctate enhancing nod- } \\
\text { ules on contrast studies } \\
\text { MR: } \\
\text { "Target appearance": central hypointensity on } \\
\text { T1WI and surrounding hyperintensity on T2WI }\end{array}$ & & $\begin{array}{l}\text { Other fungal } \\
\text { infections }\end{array}$ \\
\hline
\end{tabular}

DDD, Double-dose delayed; CVS, cardiovascular system; CMV, cytomegalovirus; NAA, $\mathrm{N}$-acetylasparate; $\mathrm{Cr}$, $\mathrm{creatine}$; $\mathrm{CHO}$, choline; PML, progressive multifocal leukoencephalopathy 
Organism/ disease
Radiologic abnormality

Extent of disease

Differential diagnosis

\subsection{Spine and Spinal Cord}

\begin{tabular}{|c|c|c|c|c|}
\hline Myelitis & $\begin{array}{l}\text { Spine/ } \\
\text { spinal cord }\end{array}$ & $\begin{array}{l}\text { MR: } \\
\text { Early stage: } \\
\text { Increase in cord diameter } \\
\text { T2WI: diffuse, ill-defined hyperintensity } \\
\text { T1WI: poorly defined enhancement on postcon- } \\
\text { trast T1WI } \\
\text { Later stage } \\
\text { Intramedullary abscess formation: decreased } \\
\text { signal intensity on T2WI with well-defined ring } \\
\text { enhancement after contrast }\end{array}$ & $\begin{array}{l}\text { - Diffuse } \\
\text { - In association with HIV } \\
\text { leukoencephalopathy } \\
(5 \%-8 \%)\end{array}$ & $\begin{array}{l}\text { Bacterial infections: } \\
\text { - Staphylococcus } \\
\text { aureus } \\
\text { - Streptococcus } \\
\text { pneumoniae } \\
\text { - Multiple sclerosis } \\
\text { - Lyme's disease } \\
\text { - Sarcoidosis of the } \\
\text { spine }\end{array}$ \\
\hline $\begin{array}{l}\text { Myco- } \\
\text { bacterium } \\
\text { tuberculosis }\end{array}$ & $\begin{array}{l}\text { Spine/ } \\
\text { spinal cord }\end{array}$ & $\begin{array}{l}\text { Intramedullary tuberculoma: varied appearance: } \\
\text { - Noncaseating granulomas: } \\
\text { T1WI: hypointense } \\
\text { T2WI: hyperintense, homogeneous enhance- } \\
\text { ment } \\
\text { - Caseating granulomas with solid center: } \\
\text { T1WI: hypointense to isointense } \\
\text { T2WI: iso- to hypointense with peripheral } \\
\text { enhancement after contrast } \\
\text { - Caseating granulomas with liquid center: } \\
\text { T1WI: hypointense } \\
\text { T2WI: hyperintense and peripheral enhance- } \\
\text { ment }\end{array}$ & $\begin{array}{l}10 \% \text { may have brain } \\
\text { lesions }\end{array}$ & - \\
\hline $\begin{array}{l}\text { Viral } \\
\text { infections }\end{array}$ & $\begin{array}{l}\text { Spine/ } \\
\text { spinal cord }\end{array}$ & $\begin{array}{l}\text { Vacuolar myelopathy } \\
\text { MR: } \\
\text { T2WI: abnormal intra medullary hyperintensity } \\
\text { in the posterior and lateral columns of the cord, } \\
\text { surrounding gray matter without cord enlarge- } \\
\text { ment or contrast enhancement }\end{array}$ & $\begin{array}{l}\text { Associated with brain } \\
\text { lesions } \\
\text { Mid/lower thoracic } \\
\text { spine }\end{array}$ & - \\
\hline $\begin{array}{l}\text { Cytomegalo- } \\
\text { virus } \\
\text { Herpes } \\
\text { simplex virus } \\
\text { (HSV-1/ } \\
\text { HSV-2) }\end{array}$ & $\begin{array}{l}\text { Spine/ } \\
\text { spinal cord }\end{array}$ & $\begin{array}{l}\text { Myeloradiculitis } \\
\text { Polyradiculomyelitis } \\
\text { CT/MR: } \\
\text { Often unremarkable; thickening of conus and } \\
\text { cauda equina. Postcontrast: strong enhancement } \\
\text { of the pia lining the cord, conus medullaris, nerve } \\
\text { roots and leptomeningis of the cord. } \\
\text { In case of necrotizing myelitis: } \\
\text { MR: } \\
\text { T2WI: hyperintense intramedullary lesions with } \\
\text { contrast enhancement } \\
\text { Nonenhanced T1WI, myelography and CT } \\
\text { myelography are usually normal }\end{array}$ & - & - \\
\hline
\end{tabular}




\begin{tabular}{lllll}
\hline $\begin{array}{l}\text { Organism/ } \\
\text { disease }\end{array}$ & $\begin{array}{l}\text { Organ } \\
\text { involved }\end{array}$ & Radiologic abnormality & Extent of disease & $\begin{array}{l}\text { Differential } \\
\text { diagnosis }\end{array}$ \\
\hline $\begin{array}{l}\text { Toxoplasmo- } \\
\text { sis (Toxoplas- }\end{array}$ & $\begin{array}{l}\text { Spine/ } \\
\text { ma gondii) }\end{array}$ & $\begin{array}{l}\text { MR: (see CNS) } \\
\text { Focal enlargement of the spinal cord with in- } \\
\text { creased T2 signal and homogeneous contrast }\end{array}$ & $\begin{array}{l}\text { Coexists with brain } \\
\text { lesions }\end{array}$ & $\begin{array}{l}\text { AIDS-related } \\
\text { lymphoma }\end{array}$ \\
\hline
\end{tabular}

\begin{tabular}{|c|c|c|c|c|}
\hline $\begin{array}{l}\text { Arachnoiditis } \\
\text { (leptomenin- } \\
\text { gitis) } \\
\text { - Neoplastic } \\
\text { - Inflamma- } \\
\text { tory: tuber- } \\
\text { culosis }\end{array}$ & $\begin{array}{l}\text { Spine/ } \\
\text { spinal cord }\end{array}$ & $\begin{array}{l}\text { MR: } \\
\text { T1WI: indistinct or absent cord outline due to in- } \\
\text { crease in signal intensity of surrounding CSF. } \\
\text { T2WI (heavily T2W FSE with fat } \\
\text { suppression): } \\
\text { CSF loculations and adhesions: } \\
\text { - In the cervical and thoracic regions with obliter- } \\
\text { ation of the arachnoidal space } \\
\text { - In lumbar region: nerve root fusion seen as } \\
\text { irregularly thickened clumped nerve roots. } \\
\text { Peripheral adherence of nerve roots to the } \\
\text { thecal sac ("featureless or empty sac"). Contrast } \\
\text { enhancement in lumbar arachnoiditis: } \\
3 \text { patterns: } \\
\text { - Smooth linear layer of enhancement outlining } \\
\text { the surface of the cord and nerve roots } \\
\text { - Nodular pattern with discrete foci of enhance- } \\
\text { ment, seen along the surface of the cord and } \\
\text { nerve roots } \\
\text { - Diffuse thick intradural enhancement which } \\
\text { completely fills the subarachnoid space }\end{array}$ & - & $\begin{array}{l}\text { AIDS-related } \\
\text { lymphoma } \\
\text { - Tethered cord }\end{array}$ \\
\hline $\begin{array}{l}\text { Discitis/ } \\
\text { osteomyelitis }\end{array}$ & $\begin{array}{l}\text { Spine/ } \\
\text { spinal cord }\end{array}$ & $\begin{array}{l}\text { Disc space narrowing with osteolytic destruction } \\
\text { of the adjacent vertebral endplates. } \\
\text { MR: } \\
\text { - T2WI: hyperintense discs adjacent vertebral } \\
\text { marrow: T1WI: hypointense and T2WI hyper- } \\
\text { intense } \\
\text { Postcontrast MR: } \\
\text { Peripheral diffuse enhancement of the disc space } \\
\text { and enhancement of the adjacent vertebral end } \\
\text { plates. Paraspinal abscess }\end{array}$ & - & $\begin{array}{l}\text { - Staphylococcus } \\
\text { aureus } \\
\text { - Mycobacterium } \\
\text { (MAI, MTb) }\end{array}$ \\
\hline $\begin{array}{l}\text { AIDS-related } \\
\text { lymphoma }\end{array}$ & $\begin{array}{l}\text { Spine/ } \\
\text { spinal cord }\end{array}$ & $\begin{array}{l}\text { MR: } \\
\text { - T2WI: enlarged cord with intramedullary iso- to } \\
\text { hyperintensity } \\
\text { - T1WI: hypointensity; patchy enhancement after } \\
\text { contrast administration }\end{array}$ & $\begin{array}{l}\text { - Epidural } \\
\text { - Leptomeningeal } \\
\text { - Intramedullary } \\
\text { Other organs involved: } \\
\text { - Skeletal system }\end{array}$ & - \\
\hline
\end{tabular}

MAI, Mycobacterium intracellulare; MTb, Mycobacterium Tuberculosis 


\begin{tabular}{lllll}
\hline $\begin{array}{l}\text { Organism/ } \\
\text { disease }\end{array}$ & $\begin{array}{l}\text { Organ } \\
\text { involved }\end{array}$ & Radiologic abnormality & Extent of disease & $\begin{array}{l}\text { Differential } \\
\text { diagnosis }\end{array}$ \\
\hline
\end{tabular}

\subsection{Cardiovascular System}

\begin{tabular}{|c|c|c|c|c|}
\hline $\begin{array}{l}\text { Pericardial } \\
\text { effusion }\end{array}$ & CVS & $\begin{array}{l}\text { Occurs in } 10 \%-15 \% \text { of HIV infection } \\
\text { Echocardiography: } \\
\text { Diastolic compression of the R atrium; echo-free/ } \\
\text { echo-poor space between parietal peri- } \\
\text { cardium and epicardium; pericardial tamponade }\end{array}$ & $\begin{array}{l}\text { Pericardium/ } \\
\text { epicardium }\end{array}$ & $\begin{array}{l}\text { Mycobacterium, } \\
\text { tuberculosis, MAI, } \\
\text { CMV, Coxsackie vi- } \\
\text { rus, herpes simplex, } \\
\text { Cryptococcus, neo- } \\
\text { formans, Salmonel- } \\
\text { la typhymurium, } \\
\text { Nocardia asteroides, } \\
\text { Listeria monocy- } \\
\text { togenes, Toxoplas- } \\
\text { ma gondii, Kaposi's } \\
\text { sarcoma, AIDS- } \\
\text { related lymphoma }\end{array}$ \\
\hline $\begin{array}{l}\text { Myocarditis, } \\
\text { cardio- } \\
\text { myopathy/ } \\
\text { ventricular } \\
\text { dysfunction }\end{array}$ & CVS & $\begin{array}{l}\text { Myocarditis (50\%) and dilated myocardiopathy } \\
(20 \%) \\
\text { Endocarditis } \\
\text { Pericarditis/pericardial effusion } \\
\text { Left ventricular enlargement } \\
\text { Chest radiograph: } \\
\text { Dilated cardiomyopathy with enlarged cardiac } \\
\text { silhouette with/without pulmonary venous con- } \\
\text { gestion/edema; cardiac decompensation } \\
\text { Echocardiography: } \\
\text { Four chamber enlargement with right/left ventri- } \\
\text { cle hypokinesia. Abnormal septum position/mo- } \\
\text { tion. Marked pulmonary hypertension: both } \\
\text { diastolic and systolic flattening of ventricular } \\
\text { septum in response to markedly abnormal } \\
\text { transeptal pressure gradient }\end{array}$ & $\begin{array}{l}\text { Myocardium } \\
\text { Endocardium } \\
\text { Pericardium }\end{array}$ & $\begin{array}{l}\text { Mycobacterium } \\
\text { tuberculosis, MAI, } \\
\text { CMV, Coxsackie } \\
\text { virus, Epstein-Barr } \\
\text { virus, herpex sim- } \\
\text { plex, Toxoplasma } \\
\text { gondii, Pneumocys- } \\
\text { tis carinii, Candida } \\
\text { albicans, Crypto- } \\
\text { coccus neoformans, } \\
\text { Aspergillus fumiga- } \\
\text { tus, Staphylococcus } \\
\text { aureus, Nocardia } \\
\text { asteroides, Strepto- } \\
\text { coccus pneumo- } \\
\text { niae, Kaposi's sar- } \\
\text { coma, AIDS-relat- } \\
\text { ed lymphoma }\end{array}$ \\
\hline $\begin{array}{l}\text { HIV-asso- } \\
\text { ciated pulmo- } \\
\text { nary hyper- } \\
\text { tension }\end{array}$ & CVS & $\begin{array}{l}\text { Chest radiograph: } \\
\text { central pulmonary arteries are enlarged; marked } \\
\text { decreased in caliber peripherally: right ventricu- } \\
\text { lar enlargement }\end{array}$ & - & РCP \\
\hline
\end{tabular}

CVS, Cardiovascular system; CMV, cytomegalovirus; MAI, Mycobacterium aviumintracellulare 


\begin{tabular}{lllll}
\hline $\begin{array}{l}\text { Organism/ } \\
\text { disease }\end{array}$ & $\begin{array}{l}\text { Organ } \\
\text { involved }\end{array}$ & Radiologic abnormality & Extent of disease & $\begin{array}{l}\text { Differential } \\
\text { diagnosis }\end{array}$
\end{tabular}

\subsection{Respiratory System}

\begin{tabular}{|c|c|c|c|c|}
\hline $\begin{array}{l}\text { Pneumocystis } \\
\text { carinii } \\
\text { pneumonia }\end{array}$ & Chest & $\begin{array}{l}\text { Normal chest radiograph: } 10 \% \\
\text { Chest radiograph: } \\
\text { Early disease: } \\
\text { Bilateral symmetric perihilar/or basal fine } \\
\text { reticulonodular pattern without pleural effusion } \\
\text { Advanced disease: } \\
\text { Diffuse homogeneous alveolar opacities } \\
\text { Late disease: } \\
\text { Asymmetrically scattered alveolar consolidation } \\
\text { (mosaic pattern); reticular pattern; thickening of } \\
\text { interlobular/interlobar interstitial tissue } \\
\text { Disseminated disease: } \\
\text { In patients with prophylactic aerosolized penta- } \\
\text { midine therapy; enlarged lymph nodes; liver/ } \\
\text { spleen punctate calcifications or areas of low } \\
\text { attenuation } \\
\text { Less common: } \\
\text { - Miliary/coarse interstitial pattern } \\
\text { - Thin-walled air containing cystic lesions (mul- } \\
\text { tiple, confluent) } \\
\text { - Pneumatoceles: } 10 \% \text { - } 34 \% \text { unilateral or less fre- } \\
\text { quently bilateral } \\
\text { - Pneumothorax ( } 1 \% \text { - } 6 \% \text { ) } \\
\text { Atypical pattern: } \\
\text { mediastinal lymphadenopathy; pleural effusions } \\
\text { (0\%-2\%) } \\
\text { pattern; sparing of lung periphery } \\
\text { Sym-raphicesolions: unilateral or less frequently } \\
\text { gramothorax }\end{array}$ & $\begin{array}{l}\text { Diffuse; upper or lower } \\
\text { zone predominance, } \\
\text { sometimes focal } \\
\text { Bilateral, often } \\
\text { symmetric, multilobar } \\
\text { Other organs involved: } \\
\text { - Liver/spleen } \\
\text { - Lymph nodes }\end{array}$ & $\begin{array}{l}\text { Other opportunistic } \\
\text { infections: } \\
\text { tuberculosis, } \\
\text { fungal infections, } \\
\text { toxoplasmosis, } \\
\text { HSV, } \\
\text { Kaposi's sarcoma, } \\
\text { CMV }\end{array}$ \\
\hline $\begin{array}{l}\text { Staphylococ- } \\
\text { cus aureus }\end{array}$ & Chest & $\begin{array}{l}\text { Chest radiograph/CT: } \\
\text { Bilateral focal parenchymal opacities (wedge- } \\
\text { shaped) with a peripheral predominance. } \\
\text { Development of cavitations; Pleural effusions/ } \\
\text { cardiomegaly uncommon }\end{array}$ & Bilateral/focal & $\begin{array}{l}\text { Other bacterial } \\
\text { infections }\end{array}$ \\
\hline $\begin{array}{l}\text { Toxo- } \\
\text { plasmosis } \\
\text { (Toxoplasma } \\
\text { gondii) }\end{array}$ & Chest & $\begin{array}{l}\text { Chest radiograph/CT: } \\
\text { Predominantly coarse, nodular opacities and } \\
\text { reticulonodular opacities; confluent consoli- } \\
\text { dations; pleural effusions, occasionally lymphad- } \\
\text { enopathy (not typical) }\end{array}$ & $\begin{array}{l}\text { Bilateral } \\
\text { Other organs involved: } \\
\text { - CNS } \\
\text { - GI tract (rare) }\end{array}$ & $\begin{array}{l}\text { - PCP } \\
\text { - Tuberculosis } \\
\text { - Fungal infections }\end{array}$ \\
\hline
\end{tabular}




\begin{tabular}{|c|c|c|c|}
\hline $\begin{array}{l}\text { Organism/ } \\
\text { disease }\end{array}$ & $\begin{array}{l}\text { Organ } \\
\text { involved }\end{array}$ & Radiologic abnormality & Extent of disease \\
\hline $\begin{array}{l}\text { Cytomegalo- } \\
\text { virus }\end{array}$ & Chest & $\begin{array}{l}\text { Chest radiograph: } \\
\text { pneumonia: reticular or reticulonodular opaci- } \\
\text { ties; areas of consolidation; tiny nodules or } \\
\text { symmetrically scattered alveolar opacities with } \\
\text { preference for central lower regions; peribron- } \\
\text { chial thickening } \\
\text { CT: } \\
\text { Bronchiectasis; "tree in bud" pattern of branch- } \\
\text { ing; small centrilobular nodules; ground glass } \\
\text { attenuation; reticular opacities, nodules, masses; } \\
\text { pneumothorax; pneumomediastinum }\end{array}$ & $\begin{array}{l}\text { Bilateral } \\
\text { Other organs involved: } \\
\text { - Adrenals } \\
\text { - GI tract(oropharynx) } \\
\text { - CNS } \\
\text { - Retina } \\
\text { - Biliary tract } \\
\text { - Liver/gallbladder }\end{array}$ \\
\hline
\end{tabular}

\begin{tabular}{|c|c|c|c|}
\hline $\begin{array}{l}\text { Herpes } \\
\text { simplex virus } \\
\text { (HSV-1, } \\
\text { HSV-2) }\end{array}$ & Chest & $\begin{array}{l}\text { Chest radiograph/CT: } \\
\text { Bilateral interstitial pattern; scattered focal } \\
\text { alveolar abnormalities; pleural effusion: rare; } \\
\text { lymphadenopathy: rare }\end{array}$ & - \\
\hline
\end{tabular}

\begin{tabular}{|c|c|c|c|c|}
\hline $\begin{array}{l}\text { Varicella } \\
\text { zoster } \\
\text { virus }\end{array}$ & Chest & $\begin{array}{l}\text { Chest radiograph/CT: } \\
\text { Bilateral, scattered, round, nodular alveolar } \\
\text { opacities with tendency to coalesce; pleural } \\
\text { effusions: rare; lymphadenopathy: rare }\end{array}$ & - & $\begin{array}{l}\cdot \mathrm{PCP} \\
\cdot \mathrm{CMV}\end{array}$ \\
\hline $\begin{array}{l}\text { Pyogenic } \\
\text { infections }\end{array}$ & Chest & $\begin{array}{l}\text { Chest radiograph/CT: } \\
\text { Diffuse heterogeneous or lobar consolidation; } \\
\text { pleural effusions; empyema; peripheral nodules/ } \\
\text { nodular infiltrates with a basalar predomi-nance; } \\
\text { cavitation does occur } \\
\text { (Staphylococcus aureus, Rhodococcus equi, and } \\
\text { anaerobes); multiple lung abscesses may occur; } \\
\text { intrathoracic lymphadenopathy: uncommon; } \\
\text { may be present in Rhodococcus infection }\end{array}$ & Diffuse & $\begin{array}{l}\text { - Haemophilus } \\
\text { influenzae } \\
\text { - Streptococcus } \\
\text { pneumoniae } \\
\text { - Nocardia } \\
\text { asteroides } \\
\text { - Legionella } \\
\text { pneumomae } \\
\text { - Corynebacterium } \\
\text { equi (Rhodo- } \\
\text { coccus) }\end{array}$ \\
\hline $\begin{array}{l}\text { Strongyloides } \\
\text { stercoralis }\end{array}$ & Chest & $\begin{array}{l}\text { Chest radiograph: } \\
\text { May be normal miliary nodules or reticular opac- } \\
\text { ities are seen. Scattered alveolar opacities and lo- } \\
\text { bar consolidations may be present in patient with } \\
\text { the hyperinfection syndrome; alveolar opacities } \\
\text { and ARDS may develop }\end{array}$ & - bilateral & PCP \\
\hline $\begin{array}{l}\text { Bacillary } \\
\text { angimatosis } \\
\text { (Bartonella } \\
\text { henselae; } \\
\text { Bartonella } \\
\text { quintana) }\end{array}$ & Chest & $\begin{array}{l}\text { Pulmonary bacillary angiomatosis } \\
\text { Bronchoscopy: } \\
\text { Violaceous endobronchial lesions, mimicking } \\
\text { Kaposi's sarcoma } \\
\text { Chest radiograph: } \\
\text { Parenchymal nodules most common; pleural } \\
\text { effusions; lymphadenopathy; chest wall masses } \\
\text { CT: } \\
\text { Lymphadenopathy and chest wall masses which } \\
\text { enhance greatly on contrast CT }\end{array}$ & $\begin{array}{l}\text { Other organs involved: } \\
\text { - Skin } \\
\text { - Lymph nodes } \\
\text { - Liver/spleen } \\
\text { - Ophthalmus, } \\
\text { conjuntivae (rare) } \\
\text { - Skeletal system }\end{array}$ & Kaposi's sarcoma \\
\hline
\end{tabular}




\begin{tabular}{|c|c|c|c|c|}
\hline $\begin{array}{l}\text { Organism/ } \\
\text { disease }\end{array}$ & $\begin{array}{l}\text { Organ } \\
\text { involved }\end{array}$ & Radiologic abnormality & Extent of disease & $\begin{array}{l}\text { Differential } \\
\text { diagnosis }\end{array}$ \\
\hline $\begin{array}{l}\text { Pasteurella } \\
\text { multocida }\end{array}$ & Chest & $\begin{array}{l}\text { Chest radiograph: } \\
\text { Focal areas of consolidation which may be } \\
\text { complicated by cavitation and pleural effusion }\end{array}$ & $\begin{array}{l}\text { Other organs involved: } \\
\text { - Soft tissue }\end{array}$ & $\begin{array}{l}\text { Otheropportunistic } \\
\text { infections }\end{array}$ \\
\hline Bordetella & Chest & $\begin{array}{l}\text { Chest radiograph: } \\
\text { Interstitial infiltrates, focal areas of } \\
\text { consolidations, occasionally cavitation }\end{array}$ & bilateral & $\begin{array}{l}\text { Other opportunistic } \\
\text { infections }\end{array}$ \\
\hline $\begin{array}{l}\text { Tuberculosis } \\
\text { (M. tuber- } \\
\text { culosis) }\end{array}$ & Chest & $\begin{array}{l}\text { Radiographic appearance of tuberculosis varies } \\
\text { with the CD4 cell count } \\
\text { Normal chest radiograph: } 5 \% \\
\text { Primary form (60\%) } \\
\text { Early disease: } \\
>200 \text { cells/mm }{ }^{3} \text { : typical pattern of post primary } \\
\text { (reactivation) tuberculosis; cavitary infiltrates } \\
\text { and consolidation usually in the apical and } \\
\text { posterior segments of the upper lobes and /or su- } \\
\text { perior segments lower lobes. Cavitation occurs. } \\
\text { Lymphadenopathy: infrequent } \\
\text { Advanced disease: } \\
<200 \text { cells/mm }{ }^{3} \text { : Diffuse coarse, nodular, reticu- } \\
\text { lonodular pattern. } \\
\text { Cavitation occurs infrequently. } \\
\text { Lymphadenopathy is often present, uni- or } \\
\text { bilateral. } \\
\text { Third form (15\%): } \\
\text { Miliary pattern: diffuse fine nodular pattern; } \\
\text { focal alveolar opacities in mid/lower lung; hilar } \\
\text { and/or mediastinal lymphadenopathy } \\
\text { CT: } \\
\text { Tuberculous lymphadenopathy: enlarged nodes } \\
\text { with central low attenuation (necrosis) and } \\
\text { peripheral ring enhancement on contrast CT; } \\
<50 \text { cells/mm }{ }^{3} \text { : disseminated tuberculosis with } \\
\text { miliary infiltrates; pleural effusions; increasing } \\
\text { lymphadenopathy }\end{array}$ & $\begin{array}{l}\text { Localized or diffuse; } \\
\text { Unilateral or bilateral } \\
\text { Other organs involved: } \\
\text { - GI tract (esophagus) } \\
\text { - Liver/spleen } \\
\text { - Lymph nodes } \\
\text { - GU tract } \\
\text { - Bones } \\
\text { - Adrenals }\end{array}$ & $\begin{array}{l}\cdot \text { PCP } \\
\cdot \text { Atypical mycobac- } \\
\text { terial infections } \\
\cdot \text { M. gordonae } \\
\cdot \text { M. fortuitum } \\
\cdot \text { M. xenopi } \\
\cdot \text { M. kansasii } \\
\text { - Fungal infections } \\
\text { - AIDS-related lym- } \\
\text { phoma }\end{array}$ \\
\hline $\begin{array}{l}\text { Myco- } \\
\text { bacterium } \\
\text { avium } \\
\text { complex }\end{array}$ & Chest & $\begin{array}{l}\text { Normal chest radiograph: } 20 \% \\
\text { Chest radiograph/CT: } \\
\text { - Diffuse, bilateral, reticulonodular opacities or } \\
\text { nodules, with or without cavities } \\
\text { - Preference for the superior lobes; focal or dif- } \\
\text { fuse alveolar disease: parenchymal consolida- } \\
\text { tion miliary pattern: less common; hilar and/or } \\
\text { mediastinal lymphadenopathy; pleural effu- } \\
\text { sions }\end{array}$ & $\begin{array}{l}\text { Disseminated, focal or } \\
\text { bilateral } \\
\text { Other organs involved: } \\
\text { - Lymph nodes } \\
\text { - Liver/spleen } \\
\text { - Peritoneum } \\
\text { - Bone marrow } \\
\text { - GI tract } \\
\text { - GU tract } \\
\text { - CNS (rare) } \\
\text { - Skin (rare) } \\
\text { - CVS (rare) }\end{array}$ & Tuberculosis \\
\hline
\end{tabular}




\begin{tabular}{|c|c|c|c|c|}
\hline $\begin{array}{l}\text { Organism/ } \\
\text { disease }\end{array}$ & $\begin{array}{l}\text { Organ } \\
\text { involved }\end{array}$ & Radiologic abnormality & Extent of disease & $\begin{array}{l}\text { Differential } \\
\text { diagnosis }\end{array}$ \\
\hline $\begin{array}{l}\text { Penicillium } \\
\text { marneffei }\end{array}$ & Chest & $\begin{array}{l}\text { Chest radiograph/CT: } \\
\text { Scattered reticulonodular or alveolar opacities } \\
\text { and/or intrathoracic lymphadenopathy ( } 80 \%) \text {; } \\
\text { single nodule/mass with/without cavitation or } \\
\text { focal segmental consolidation (less frequent); } \\
\text { pleural effusion; miliary pattern }\end{array}$ & $\begin{array}{l}\text { Solitary/multiple } \\
\text { lesions, bilateral, diffuse } \\
\text { Other organs involved: } \\
\text { - CNS } \\
\text { - Lymph nodes } \\
\text { - Liver/spleen } \\
\text { - Bone marrow }\end{array}$ & $\begin{array}{l}\text { - Toxoplasmosis } \\
\text { - PCP } \\
\text { - Tuberculosis }\end{array}$ \\
\hline $\begin{array}{l}\text { Nocardiosis } \\
\text { (Nocardia } \\
\text { asteroides; } \\
\text { Nocardia } \\
\text { brasiliensis) }\end{array}$ & Chest & $\begin{array}{l}\text { Chest radiograph/CT: } \\
\text { - Large areas of segmental consolidations, in- } \\
\text { volving several lobes } \\
\text { - Diffuse interstitial pattern or solitary defined } \\
\text { mass often, with cavitation; pleural or pericar- } \\
\text { dial effusion may occur }\end{array}$ & $\begin{array}{l}\text { Unilateral/focal } \\
\text { Other organs involved: } \\
\text { - CNS } \\
\text { - Skin and soft tissue in- } \\
\text { fections }\end{array}$ & $\begin{array}{l}\text { - Other opportunis- } \\
\text { tic infections } \\
\text { - Tuberculosis }\end{array}$ \\
\hline $\begin{array}{l}\text { Histo- } \\
\text { plasmosis } \\
\text { (Histoplasma } \\
\text { capsulatum) }\end{array}$ & Chest & $\begin{array}{l}\text { Chest radiograph/CT: } \\
\text { Normal in } 50 \% \\
\text { - Diffuse heterogeneous opacities } \\
\text { - Diffuse small lung parenchymal nodules } \\
\text { - Linear irregular and airspace opacities } \\
\text { less common } \\
\text { - Miliary pattern; focal infiltrates } \\
\text { - Hilar/mediastinal lymphadenopathy } \\
\text { (uncommon) } \\
\text { - Pleural effusions (uncommon) }\end{array}$ & $\begin{array}{l}\text { Disseminated } \\
\text { More diffuse than focal } \\
\text { Other organs involved: } \\
\text { - Bone marrow }\end{array}$ & $\begin{array}{l}\text { Otheropportunistic } \\
\text { infections }\end{array}$ \\
\hline $\begin{array}{l}\text { Coccidio- } \\
\text { idomycosis } \\
\text { (Coccidioides } \\
\text { immitis) }\end{array}$ & Chest & $\begin{array}{l}\text { Chest radiograph/CT: } \\
\text { Normal in } 70 \% \\
\text { - Reticulonodular lung parenchymal opacities } \\
\text { - Focal alveolar opacities } \\
\text { - Discrete nodules } \\
\text { - Hilar lymphadenopathy } \\
\text { - Pulmonary thin-walled cavity and pleural } \\
\text { effusion occur }\end{array}$ & $\begin{array}{l}\text { Diffuse } \\
\text { Other organs involved: } \\
\text { - Meninges } \\
\text { - Skin }\end{array}$ & $\begin{array}{l}\text { Otheropportunistic } \\
\text { infections }\end{array}$ \\
\hline $\begin{array}{l}\text { Aspergillosis } \\
\text { (Aspergillus } \\
\text { fumigatus) }\end{array}$ & Chest & $\begin{array}{l}\text { Chest radiograph/CT: } \\
\text { - Ill-defined pleural based nodules or masses } \\
\text { - Areas of consolidation } \\
\text { - Multiple thick-walled cavities ("air crescent } \\
\text { sign") in upper lobe less common: } \\
\text { - Pleural effusions (uncommon) } \\
\text { - Lymphadenopathy (uncommon) }\end{array}$ & $\begin{array}{l}\text { Diffuse systemic } \\
\text { dissemination (35\%) }\end{array}$ & $\begin{array}{l}\text { Other opportunis- } \\
\text { tic infections } \\
\text { - Tuberculosis }\end{array}$ \\
\hline $\begin{array}{l}\text { Blasto- } \\
\text { mycosis }\end{array}$ & Chest & $\begin{array}{l}\text { Chest radiograph/CT: } \\
\text { - Focal airspace opacities or masses } \\
\text { - Diffuse nodular opacities } \\
\text { - Cavitation } \\
\text { - Lymphadenopathy and pleural effusions: } \\
\text { less common }\end{array}$ & Disseminated disease & - \\
\hline
\end{tabular}




\begin{tabular}{|c|c|c|c|c|}
\hline $\begin{array}{l}\text { Organism/ } \\
\text { disease }\end{array}$ & $\begin{array}{l}\text { Organ } \\
\text { involved }\end{array}$ & Radiologic abnormality & Extent of disease & $\begin{array}{l}\text { Differential } \\
\text { diagnosis }\end{array}$ \\
\hline $\begin{array}{l}\text { Kaposi's } \\
\text { sarcoma }\end{array}$ & Chest & $\begin{array}{l}\text { Chest radiograph: } \\
\text { Early disease: } \\
\text { - Diffuse, bilateral, poorly defined, reticulonodu- } \\
\text { lar opacities (1-2 cm) in a perihilar distribution } \\
\text { - Coarsening bronchovascular bundles and peri- } \\
\text { bronchial cuffing } \\
\text { - Bilateral scattered mostly round opacities, } \\
\text { whose delineation varies in definition } \\
\text { - Parenchymal abnormalities coarser in nature } \\
\text { than those in PCP } \\
\text { Advanced disease: } \\
\text { - Lobar consolidation; Kerley B lines } \\
\text { - Pleural effusions, mostly bilateral, often in large } \\
\text { amounts (<40\%) } \\
\text { - Intrathoracic lymphadenopathy ( } 30 \% \text { ) } \\
\text { CT: } \\
\text { - Ill-defined nodules; } \\
\text { - areas of consolidation along a predominantly } \\
\text { bronchovascular distribution; peribronch } \\
\text { ovascular thickening, radiating from the } \\
\text { perihilar region } \\
\text { - Subpleural nodules } \\
\text { - Ground-glass attenuation adjacent to nodules/ } \\
\text { masses (hemorrhage) }\end{array}$ & $\begin{array}{l}\text { Bilateral } \\
\text { Unilateral }(<10 \%) \\
\text { Other organs involved: } \\
\text { - Mucocutaneous } \\
\text { - Sternum } \\
\text { - Ribs } \\
\text { - Thoracic spine } \\
\text { - GI tract } \\
\text { - Liver/spleen } \\
\text { - Lymph nodes } \\
\text { Pulmonary Kaposi's } \\
\text { sarcoma is preceded in } \\
95 \% \text { by mucous mem- } \\
\text { brane/skin lesions }\end{array}$ & $\begin{array}{l}\cdot \text { PCP } \\
\cdot \text { CMV } \\
\text { - NHL } \\
\text { - Typical/ atypical } \\
\text { mycobacterial in- } \\
\text { fections } \\
\text { - Fungal infections }\end{array}$ \\
\hline $\begin{array}{l}\text { AIDS-related } \\
\text { lymphoma } \\
\text { (B cell } \\
\text { or T cell } \\
\text { lymphoma) }\end{array}$ & Chest & $\begin{array}{l}\text { Intrathoracic involvement: } \\
10 \%-50 \% \\
\text { Chest radiograph/CT: } \\
\text { - Lung parenchymal consolidation } \\
\text { - Unilateral or bilateral solitary or multiple } \\
\text { masses and nodules, which may rapidly } \\
\text { progress } \\
\text { - Pleural effusion/masses ( } 60 \%) \text {; air broncho- } \\
\text { gram; chest wall invasion } \\
\text { - Axillary/hilar/mediastinal lymphadenopathy } \\
\text { (50\%) } \\
\text { - Less frequent: interstitial infiltrates; alveolar } \\
\text { opacities; pericardial effusion/masses; myocar- } \\
\text { dial involvement }\end{array}$ & $\begin{array}{l}\text { Unilateral or bilateral; } \\
\text { solitary or multiple le- } \\
\text { sions } \\
\text { Other organs involved: } \\
\text { - CNS } \\
\text { - GI tract } \\
\text { - Liver, spleen } \\
\text { - Pancreas } \\
\text { - Retroperitoneum }\end{array}$ & $\begin{array}{l}\text { - Typical/ atypical } \\
\text { mycobacterial } \\
\text { infections } \\
\text { - PCP } \\
\text { - Fungal infections }\end{array}$ \\
\hline $\begin{array}{l}\text { Lymphocytic } \\
\text { interstitial } \\
\text { pneumonia }\end{array}$ & Chest & $\begin{array}{l}\text { Normal chest radiograph: } 50 \% \\
\text { Chest radiograph: } \\
\text { Nonspecific findings: } \\
\text { - Fine to coarse reticular/ reticulonodular } \\
\text { interstitial opacities, } \\
\text { - Scattered alveolar/ground-glass opacities } \\
\text { - Pleural effusion: unusual } \\
\text { - No intrathoracic lymphadenopathy } \\
\text { CT: } \\
\text { Small nodules are the predominant findings; } \\
\text { peribronchovascular in distribution; areas of } \\
\text { ground-glass opacities }\end{array}$ & $\begin{array}{l}\text { Diffuse, bilateral } \\
\text { Most frequent in } \\
\text { children }\end{array}$ & $\begin{array}{l}\text { Other opportu- } \\
\text { nistic infections } \\
\text { - PCP }\end{array}$ \\
\hline
\end{tabular}




\begin{tabular}{|c|c|c|c|c|}
\hline $\begin{array}{l}\text { Organism/ } \\
\text { disease }\end{array}$ & $\begin{array}{l}\text { Organ } \\
\text { involved }\end{array}$ & Radiologic abnormality & Extent of disease & $\begin{array}{l}\text { Differential } \\
\text { diagnosis }\end{array}$ \\
\hline Lung cancer & Chest & $\begin{array}{l}\text { Chest radiograph: } \\
\text { Peripheral or central nodule or mass; pleural } \\
\text { effusion } \\
\text { CT: } \\
\text { Lung mass, extending to the pleura }\end{array}$ & - & - \\
\hline
\end{tabular}

HSV, Herpes simplex virus; CMV, cytomegalovirus; PCP, Pneumocystis carinii pneumonia; ARDS, adult respiratory distress syndrome; CVS, cardiovascular system; NHL, non-Hodgkin's lymphoma

\subsection{Luminal Gastrointestinal Tract}

\begin{tabular}{|c|c|c|c|c|}
\hline $\begin{array}{l}\text { Candida } \\
\text { (Candida } \\
\text { albicans) }\end{array}$ & $\begin{array}{l}\text { Oropharynx/ } \\
\text { esophagus }\end{array}$ & $\begin{array}{l}\text { Endoscopy/barium studies: } \\
\text { Oral thrush } \\
\text { Mild disease: } \\
\text { - Edematous folds } \\
\text { - Minimal mucosal plaques, covering a friable } \\
\text { erythematous mucosa } \\
\text { - Coarse filling defects, oriented along the long } \\
\text { axis of the esophagus } \\
\text { - Ulcerations } \\
\text { Moderate disease: } \\
\text { - Diffuse mucosal plaques; fine longitudinal ul- } \\
\text { cerations } \\
\text { Severe/advanced disease: } \\
\text { - Fold thickening } \\
\text { - Abnormal motility } \\
\text { - Diffuse deep ulcerations (longitudinal); “cob- } \\
\text { blestone" appearance (submucosal edema) } \\
\text { - Extensive diffuse or focally clustered plaques } \\
\text { ("shaggy esophagus"); barium trapping within } \\
\text { plaques and pseudomembranes in conjunction } \\
\text { with deep ulceration and mucosal sloughing } \\
\text { Endstage of disease: } \\
\text { Polypoid lesions; strictures; mucosal "bridging" }\end{array}$ & $\begin{array}{l}\text { Focal or confluent } \\
\text { Other organs involved: } \\
\text { - Skin } \\
\text { - Respiratory tract } \\
\text { - CNS }\end{array}$ & $\begin{array}{l}\text { Herpes } \\
\text { simplex virus }\end{array}$ \\
\hline $\begin{array}{l}\text { Herpes } \\
\text { simplex virus } \\
\text { (HSV-1, } \\
\text { HSV-2) }\end{array}$ & $\begin{array}{l}\text { Oropharnx/ } \\
\text { esophagus }\end{array}$ & $\begin{array}{l}\text { Endoscopy/barium studies: } \\
\text { Mild disease: } \\
\text { - Multiple, scattered, diamond/stellate-shaped } \\
\text { shallow ulcers, separated by normal mucosa; } \\
\text { lucent halo of edema } \\
\text { Advanced disease: } \\
\text { - Diffuse nodularity/ulcerations with "cob- } \\
\text { blestoning"; inflammatory exudates } \\
\text { - Irregular esophageal contour similar to CMV }\end{array}$ & $\begin{array}{l}\text { Focal or diffuse } \\
\text { Other organs involved: } \\
\text { - Mucocutaneous } \\
\text { - Perianal region }\end{array}$ & $\begin{array}{l}\text { - Candida } \\
\cdot \text { CMV }\end{array}$ \\
\hline
\end{tabular}




\begin{tabular}{|c|c|c|c|c|}
\hline $\begin{array}{l}\text { Organism/ } \\
\text { disease }\end{array}$ & $\begin{array}{l}\text { Organ } \\
\text { involved }\end{array}$ & Radiologic abnormality & Extent of disease & $\begin{array}{l}\text { Differential } \\
\text { diagnosis }\end{array}$ \\
\hline \multirow[t]{3}{*}{$\begin{array}{l}\text { Cytomegalo- } \\
\text { virus }\end{array}$} & $\begin{array}{l}\text { Esophagus/ } \\
\text { stomach }\end{array}$ & $\begin{array}{l}\text { CMV gastritis } \\
\text { Endoscopy/esophagogram: } \\
\text { Diffuse granular mucosa, due to clustered super- } \\
\text { ficial erosions and/or aphthous ulcers; irregular } \\
\text { thickening of mucosal folds; shallow, poorly de- } \\
\text { fined, diamond-shaped ulcers, irregular thicken- } \\
\text { ing of mucosal folds; nodular wall thickening; } \\
\text { tiny ulcers; granularity of mucosa; narrowing of } \\
\text { lumen with limited distensibility with attenua- } \\
\text { tion }\end{array}$ & $\begin{array}{l}\text { Distal esophagus with } \\
\text { extension into esopha- } \\
\text { gogastricjunction } \\
\text { Predilection: antrum } \\
\text { Other organs involved: } \\
\text { - Adrenals } \\
\text { - Respiratory tract } \\
\text { - CNS } \\
\text { - Retina } \\
\text { - Biliary tract } \\
\text { - Liver/gallbladder } \\
\text { Focal or diffuse: } \\
\text { common }\end{array}$ & $\begin{array}{l}\text { - Idiopathic } \\
\text { - HIV } \\
\text { - Herpes } \\
\text { - Candida } \\
\text { - Cryptosporidium }\end{array}$ \\
\hline & $\begin{array}{l}\text { Small intes- } \\
\text { tine }\end{array}$ & $\begin{array}{l}\text { Barium studies } \\
\text { Mild dilatation: edematous submucosal nodules } \\
(0.25-0.75 \mathrm{~cm}) \text {; separation of loops; shallow or } \\
\text { deep, round or serpiginous ulceration of various } \\
\text { size/depth } \\
\text { Late stage: narrowing of lumen; fistula, pneuma- } \\
\text { tosis intestinalis }\end{array}$ & $\begin{array}{l}\text { Segmental or diffuse } \\
\text { Predilection: terminal } \\
\text { ileum }\end{array}$ & Cryptosporidium \\
\hline & $\begin{array}{l}\text { Colon/ano- } \\
\text { rectum }\end{array}$ & $\begin{array}{l}\text { Mild disease: } \\
\text { Barium studies: } \\
\text { Diffuse mucosal granularity; cecal spasm; irregu- } \\
\text { lar thickening of mucosal folds (edema); super- } \\
\text { ficial or deep punctate or linear ulcerations; } \\
\text { aphthous ulcers } \\
\text { CT: } \\
\text { Low-density edematous bowel wall; marked } \\
\text { mucosal/serosal enhancement } \\
\text { Severe/advanced disease: } \\
\text { Barium studies: } \\
\text { Large ulcers; skip lesions; areas of mass effect } \\
\text { (granulation tissue/submucosal hemorrhage); } \\
\text { nodular filling defects (pseudomembranes) } \\
\text { CT: } \\
\text { Increased density in bowel wall (hemorrhage); } \\
\text { thickening of bowel wall } \\
\text { Late-stage disease: } \\
\text { Barium studies } \\
\text { CT: } \\
\text { Narrowing of the lumen }\end{array}$ & $\begin{array}{l}\text { Segmental or diffuse } \\
\text { Common predilection: } \\
\text { - Ascending colon/ } \\
\text { cecum/terminal ileum } \\
\text { - Sometimes entire colon }\end{array}$ & \\
\hline
\end{tabular}




\begin{tabular}{|c|c|c|c|c|}
\hline $\begin{array}{l}\text { Organism/ } \\
\text { disease }\end{array}$ & $\begin{array}{l}\text { Organ } \\
\text { involved }\end{array}$ & Radiologic abnormality & Extent of disease & $\begin{array}{l}\text { Differential } \\
\text { diagnosis }\end{array}$ \\
\hline $\begin{array}{l}\text { Idiopathic } \\
\text { HIV }\end{array}$ & $\begin{array}{l}\text { Esophagus/ } \\
\text { anorectum }\end{array}$ & $\begin{array}{l}\text { Barium studies: } \\
\text { Giant }(2 \mathrm{~cm}) \text { well-defined flat/shallow ulceration, } \\
\text { surrounded by thin rim of edema with surround- } \\
\text { ing normal mucosa } \\
\text { Barium studies/CT: } \\
\text { "Idiopathic AIDS enteropathy"; nonspecific mild } \\
\text { small bowel wall thickening }\end{array}$ & $\begin{array}{l}\text { Usually solitary; can be } \\
\text { multiple } \\
\text { Predilection: lower } \\
\text { esophagus }\end{array}$ & $\begin{array}{l}\cdot \text { CMV } \\
\cdot \text { HSV } \\
\cdot \text { Mycobacterial in- } \\
\text { fection }\end{array}$ \\
\hline $\begin{array}{l}\text { Crypto- } \\
\text { sporidiosis } \\
\text { (Cryptosporid } \\
\text { ium) }\end{array}$ & $\begin{array}{l}\text { Small } \\
\text { intestine }\end{array}$ & $\begin{array}{l}\text { Barium studies: } \\
\text { Mild small bowel dilatation; hypersecretion; } \\
\text { "sprue-like appearance" } \\
\text { CT: } \\
\text { Small bowel wall thickening/ dilatation small } \\
\text { bowel/increased intraluminal fluids; no associat- } \\
\text { ed mesenteric lymphadenopathy }\end{array}$ & $\begin{array}{l}\text { Diffuse } \\
\text { Predilection: proximal } \\
\text { bowel } \\
\text { Other organs involved: } \\
\text { - Duodenum } \\
\text { - Colon } \\
\text { - Biliary tract } \\
\text { - Respiratory tract }\end{array}$ & $\begin{array}{l}\text { Otheropportunistic } \\
\text { infections: } \\
\text { - Giardiasis } \\
\text { - Isospora belli }\end{array}$ \\
\hline $\begin{array}{l}\text { Mycobacteri- } \\
\text { um avium- } \\
\text { intracellulare } \\
\text { complex }\end{array}$ & Esophagus & $\begin{array}{l}\text { Esophagogram: } \\
\text { Focal extrinsic mass impression; longitudinal } \\
\text { deep ulcerations; sinus tract to the mediastinum/ } \\
\text { esophago-trachial fistulae; traction diverticula; } \\
\text { strictures in chronic disease; fistula formation }\end{array}$ & $\begin{array}{l}\text { Focal } \\
\text { Predilection: middle } \\
\text { third of the esophagus, } \\
\text { duodenum, small bowel } \\
\text { Other organs involved: } \\
\text { - Lymph nodes } \\
\text { - Liver/spleen } \\
\text { - Peritoneum } \\
\text { - Bone marrow } \\
\text { - Respiratory tract } \\
\text { - GU tract } \\
\text { - CNS (rare) } \\
\text { - Skin (rare) } \\
\text { - CVS (rare) }\end{array}$ & $\begin{array}{l}\text { - Idiopathic } \\
\text { - HIV } \\
\cdot \text { CMV } \\
\text { - M. tuberculosis }\end{array}$ \\
\hline & $\begin{array}{l}\text { Stomach/ } \\
\text { duodenal } \\
\text { bulb }\end{array}$ & $\begin{array}{l}\text { Barium studies: } \\
\text { Ulceration; hypertrophic fibrotic encasement; } \\
\text { bulky gastric mass extending into mesentery. } \\
\text { Thickening of mucosal folds; aphthous ulcers, } \\
\text { outlet obstruction }\end{array}$ & $\begin{array}{l}\text { Segmental } \\
\text { Hepatosplenomegaly } \\
\text { common }\end{array}$ & - Crohn's disease \\
\hline & $\begin{array}{l}\text { Small } \\
\text { intestine }\end{array}$ & $\begin{array}{l}\text { Barium studies/CT: } \\
\text { Mild dilatation with irregular fold thickening; } \\
\text { separation/displacement of bowel loops due to } \\
\text { low attenuation necrotic lymphadenopathy; } \\
\text { spasm, irregularity; fine nodularity; mild hyper- } \\
\text { tension with segmental/ flocculation of barium; } \\
\text { appendiceal mass?; "pseudo-Whipple's" disease } \\
\text { CT: } \\
\text { Large mesenteric and retroperitoneal low-atten- } \\
\text { uation necrotic lymphadenopathy; marked } \\
\text { hepatosplenomegaly }\end{array}$ & $\begin{array}{l}\text { Segmental } \\
\text { Predilection } \\
\text { - Ileocecal area } \\
\text { - Jejunoileum } \\
\text { Microabscesses in liver/ } \\
\text { spleen are an uncom- } \\
\text { mon finding }\end{array}$ & $\begin{array}{l}\text { Otheropportunistic } \\
\text { infections: } \\
\text { - PCP } \\
\text { - Giardiasis } \\
\text { - Isospora belli } \\
\text { - CMV }\end{array}$ \\
\hline
\end{tabular}




\begin{tabular}{|c|c|c|c|c|}
\hline $\begin{array}{l}\text { Organism/ } \\
\text { disease }\end{array}$ & $\begin{array}{l}\text { Organ } \\
\text { involved }\end{array}$ & Radiologic abnormality & Extent of disease & $\begin{array}{l}\text { Differential } \\
\text { diagnosis }\end{array}$ \\
\hline $\begin{array}{l}\text { Kaposi's } \\
\text { sarcoma }\end{array}$ & $\begin{array}{l}\text { Oropharynx/ } \\
\text { esophagus/ } \\
\text { stomach/ } \\
\text { duodenum/ } \\
\text { small bowel/ } \\
\text { colon/ } \\
\text { anorectum }\end{array}$ & $\begin{array}{l}\text { Barium studies: } \\
\text { Circumferential thickening of cecal wall and } \\
\text { terminal ileum; fistula formation } \\
\text { CT: } \\
\text { Regional low-attenuation necrotic } \\
\text { lymphadenopathy } \\
\text { Barium studies: } \\
\text { Early disease: } \\
\text { Flat lesions, not demonstrated on barium stud- } \\
\text { ies; granularity of mucosa } \\
\text { Advanced disease: } \\
\text { Irregular thickening of mucosal folds; discrete } \\
\text { sharp mucosal nodules ( } 6 \text { mm- } 3 \text { cm) with or } \\
\text { without central umbilication (bull's eye/target } \\
\text { appearance); normal intervening mucosa; nodu- } \\
\text { lar wall thickening or small bowel; sometimes } \\
\text { large, bulky polypoid, segmental masses; } \\
\text { narrowing of lumen } \\
\text { CT: } \\
\text { High-attenuation lymphadenopathy complica- } \\
\text { tions: intestinal perforation }\end{array}$ & $\begin{array}{l}\text { Segmental } \\
\text { Predilection: ileocecal } \\
\text { region } \\
\text { Diffuse } \\
\text { Other organs involved } \\
\text { - Respiratory tract } \\
\text { - Lymph nodes } \\
\text { - Liver/spleen } \\
\text { - CVS } \\
\text { - GU tract } \\
\text { - Skin }\end{array}$ & $\begin{array}{l}\text { Opportunistic in- } \\
\text { fections } \\
\text { - Crohn's disease } \\
\text { - AIDS-related } \\
\text { lymphoma } \\
\text { - MAC } \\
\text { - Multiple polyps } \\
\text { - Hematogenous } \\
\text { metastasis }\end{array}$ \\
\hline $\begin{array}{l}\text { AIDS-related } \\
\text { lymphoma }\end{array}$ & $\begin{array}{l}\text { Stomach/ } \\
\text { small intes- } \\
\text { tine/colon/ } \\
\text { anorectum }\end{array}$ & $\begin{array}{l}\text { Barium studies: } \\
\text { Diffuse wall thickening mesenteric polypoid } \\
\text { lesions simulating adenocarcinoma; loss of } \\
\text { mucosal pattern; irregular fold thickening; } \\
\text { discrete } \\
\text { Penetrating ulcers; Narrowing of lumen } \\
\text { CT: } \\
\text { Extraluminal extent of enteric lymphomas; } \\
\text { abundant retroperitoneal or mesenteric lym- } \\
\text { phadenopathy. } \\
\text { Acute complications: } \\
\text { Perforation, obstruction, intussuseption }\end{array}$ & $\begin{array}{l}\text { Other organs involved: } \\
\text { - CNS } \\
\text { - Bone marrow } \\
\text { - Abdominal viscera: } \\
\text { kidney (hydronephro- } \\
\text { sis due to obstructing } \\
\text { lymphnodes) } \\
\text { - Anorectum/colon } \\
\text { - Nonspecific hepato- } \\
\text { splenomegaly may be } \\
\text { present }\end{array}$ & $\begin{array}{l}\text { Kaposi's sarcoma } \\
\text { - Mycobacterium } \\
\text { tuberculosis }\end{array}$ \\
\hline
\end{tabular}

HSV, Herpes simplex virus; CMV, cytomegalovirus; PCP, Pneumocystis carinii pneumonia; CVS, cardiovascular system; MAC, Mycobacterium avium-intracellulare complex 


\begin{tabular}{|llll}
\hline $\begin{array}{l}\text { Organism/ } \\
\text { disease }\end{array}$ & $\begin{array}{l}\text { Organ } \\
\text { involved }\end{array}$ & $\begin{array}{l}\text { Radiologic abnormality } \\
\text { Extent of disease }\end{array}$ & $\begin{array}{l}\text { Differential } \\
\text { diagnosis }\end{array}$ \\
\hline
\end{tabular}

\subsection{Liver/Spleen/Biliary tract}

\begin{tabular}{|c|c|c|c|c|}
\hline $\begin{array}{l}\text { Pneumocystis } \\
\text { (Pneumo- } \\
\text { cystis carinii) }\end{array}$ & Liver/spleen & $\begin{array}{l}\text { US: } \\
\text { Numerous nodules (liver/spleen/kidneys) } \\
\text { Usually hypoechoic }>2 \mathrm{~cm} \text {, multiple tiny } \\
\text { echogenic foci without shadowing } \\
\text { CT: } \\
\text { Calcifications (liver/spleen), usually hypodensity } \\
\text { nodules, }<2 \mathrm{~cm} \text { in both liver and spleen }\end{array}$ & $\begin{array}{l}\text { Focal } \\
\text { Other organs involved: } \\
\text { - CNS } \\
\text { - Bone marrow } \\
\text { - Respiratory tract } \\
\text { - GU tract } \\
\text { - Adrenal glands } \\
\text { - Retina } \\
\text { - Thyroid } \\
\text { - Parathyroid glands } \\
\text { - Gallbladder } \\
\text { - Pancreas }\end{array}$ & $\begin{array}{l}\text { - Candida albicans } \\
\text { - Aspergillus } \\
\text { fumigatus } \\
\text { - MAC } \\
\text { - Cytomegalo virus } \\
\text { - Mycobacterium } \\
\text { tuberculosis } \\
\text { - Bacillary angiom- } \\
\text { atosis } \\
\text { - Fungal infections } \\
\text { - Kaposi's sarcoma } \\
\text { - AIDS-related } \\
\text { lymphoma } \\
\text { - Smooth muscle } \\
\text { tumor }\end{array}$ \\
\hline $\begin{array}{l}\text { Bacillary } \\
\text { angiomatosis } \\
\text { (peliosis) } \\
\text { (Bartonella } \\
\text { henselae) }\end{array}$ & Liver/spleen & $\begin{array}{l}\text { US: } \\
\text { Nonspecific! } \\
\text { Heterogeneous liver with hyper- and hypoechoic } \\
\text { regions } \\
\text { CT: } \\
\text { Hypodense with isodense lesions after } \\
\text { attenuation }\end{array}$ & $\begin{array}{l}\text { Rare } \\
\text { - Associated with chron- } \\
\text { ic diseases (malignan- } \\
\text { cies, tuberculosis etc.) } \\
\text { Other organs involved: } \\
\text { - Respiratory tract } \\
\text { - Mediastinum } \\
\text { - CNS (rare) } \\
\text { - Ophtalmic (rare) } \\
\text { - Skeletal system }\end{array}$ & $\begin{array}{l}\text { - Mycobacterium } \\
\text { tuberculosis } \\
\text { - MAC } \\
\text { - PCP } \\
\text { - Fungal infections } \\
\text { - Kaposi's sarcoma } \\
\text { - AIDS-related lym- } \\
\text { phoma } \\
\text { - Smooth muscle } \\
\text { tumor }\end{array}$ \\
\hline $\begin{array}{l}\text { Fungal } \\
\text { infections }\end{array}$ & Liver/spleen & $\begin{array}{l}\text { US/CT: } \\
\text { Multiple small hypoechoic/hypodense nodules } \\
<2 \mathrm{~cm} \text { (liver/spleen); hepatosplenomegaly }\end{array}$ & $\begin{array}{l}\text { Diffuse } \\
\text { Other organs involved: } \\
\text { - Respiratory tract } \\
\text { - Bone marrow } \\
\text { - GI tract } \\
\text { - CNS } \\
\text { - Lymph nodes } \\
\text { - Liver/spleen }\end{array}$ & $\begin{array}{l}\text { - Mycobacterium } \\
\text { tuberculosis } \\
\cdot \text { MAC } \\
\text { - Bacillary } \\
\text { angiomatosis } \\
\cdot \text { PCP } \\
\cdot \text { Kaposi's sarcoma } \\
\text { - AIDS-related } \\
\text { lymphoma } \\
\text { - Histoplasma } \\
\text { capsulatum } \\
\cdot \text { Coccidioides } \\
\text { immitis } \\
\text { - Cryptococcus neo- } \\
\text { formans } \\
\text { - Candida albicans }\end{array}$ \\
\hline
\end{tabular}




\begin{tabular}{|c|c|c|c|c|}
\hline $\begin{array}{l}\text { Organism/ } \\
\text { disease }\end{array}$ & $\begin{array}{l}\text { Organ } \\
\text { involved }\end{array}$ & Radiologic abnormality & Extent of disease & $\begin{array}{l}\text { Differential } \\
\text { diagnosis }\end{array}$ \\
\hline \multirow[t]{2}{*}{$\begin{array}{l}\text { Cytomegalo- } \\
\text { virus }\end{array}$} & Liver/spleen & $\begin{array}{l}\text { US/CT: } \\
\text { Multiple focal small echogenic/hypoechoic/low- } \\
\text { attenuation lesions }\end{array}$ & $\begin{array}{l}\text { Focal or diffuse } \\
\text { Other organs involved: } \\
\text { - Luminal GI tract } \\
\text { - Adrenals } \\
\text { - Respiratory tract } \\
\text { - CNS } \\
\text { - Retina } \\
\text { - Pancreas }\end{array}$ & $\begin{array}{l}\text { Otheropportunistic } \\
\text { infections }\end{array}$ \\
\hline & Biliary tract & $\begin{array}{l}E R C P \text { : } \\
\text { AIDS-related cholangiopathy; sclerosing cholan- } \\
\text { gitis; irregular dilatation of the CBD; decreased } \\
\text { arborization of intrahepatic ducts; irregular/ } \\
\text { "brush border" of biliary mucosa; multiple vesic- } \\
\text { ular filling defects; thickened duct wall of intra/ } \\
\text { extrahepatic bile ducts; papillary stenosis; acal- } \\
\text { culous cholecystitis; extrahepatic bile duct } \\
\text { strictures }(1-2 \mathrm{~cm})\end{array}$ & Segmental/diffuse & $\begin{array}{l}\text { - Microsporidium } \\
\text { - Cryptosporidium } \\
\text { - MAC } \\
\text { - Isospora belli } \\
\text { - Primary sclerosing } \\
\text { cholangitis }\end{array}$ \\
\hline $\begin{array}{l}\text { Myco- } \\
\text { bacterium } \\
\text { avium-intra- } \\
\text { cellulare } \\
\text { complex }\end{array}$ & Liver/spleen & $\begin{array}{l}\text { US: } \\
\text { Multiple tiny echogenic foci in liver/spleen and } \\
\text { kidneys } \\
\text { CT: } \\
\text { Hypoechoic/hypodense nodules }<2 \mathrm{~cm} \text {; } \\
\text { hepatosplenomegaly; porta hepatis and } \\
\text { pancreatic lymphadenopathy }\end{array}$ & $\begin{array}{l}\text { Diffuse/focal } \\
\text { Other organs involved } \\
\text { - Lymph nodes } \\
\text { - Peritoneum } \\
\text { - Bone marrow } \\
\text { - GI tract } \\
\text { - Respiratory tract } \\
\text { - GU tract (kidneys) } \\
\text { - CNS (rare } \\
\text { - Skin (rare) } \\
\text { - CVS (rare) }\end{array}$ & $\begin{array}{l}\text { - Mycobacterium } \\
\text { tuberculosis } \\
\text { - Bacillary } \\
\text { angiomatosis } \\
\text { - P. carinii } \\
\quad \text { (extrapulmonary) } \\
\text { - Fungal infections } \\
\text { - Kaposi's sarcoma } \\
\text { - AIDS-related } \\
\text { lymphoma }\end{array}$ \\
\hline $\begin{array}{l}\text { Myco- } \\
\text { bacterium } \\
\text { tuberculosis }\end{array}$ & Liver/spleen & $\begin{array}{l}\text { US/CT: } \\
\text { Hypoechoic/hypodense nodules }<2 \mathrm{~cm} \text {; } \\
\text { hepatosplenomegaly; often enlarged retro- } \\
\text { peritoneal and mesenteric lymph nodes with } \\
\text { central necrosis (low-density nodes); con- } \\
\text { comitant segmental ileocecal thickening }\end{array}$ & $\begin{array}{l}\text { Diffuse/multifocal } \\
\text { Other organs involved: } \\
\text { - Respiratory tract } \\
\text { - Lymph nodes } \\
\text { - GU tract } \\
\text { - Adrenals } \\
\text { - Pancreas } \\
\text { - Bone marrow } \\
\text { - GI tract } \\
\text { - CNS } \\
\text { - Soft tissue }\end{array}$ & $\begin{array}{l}\text { - MAC } \\
\text { - Bacillary angiom- } \\
\text { atosis } \\
\text { - } \text { P. carinii } \\
\text { - Fungal infections } \\
\text { - AIDS-related lym- } \\
\text { phoma }\end{array}$ \\
\hline $\begin{array}{l}\text { Kaposi's } \\
\text { sarcoma }\end{array}$ & $\begin{array}{l}\text { Liver/spleen } \\
\text { Bile duct } \\
\text { Gallbladder }\end{array}$ & $\begin{array}{l}\text { US: } \\
\text { Small (5-12 mm) hyperechoic periportal nodules } \\
\text { in liver/spleen } \\
\text { Increased periportal echogenicity } \\
\text { CT: } \\
\text { Low-attenuation periportal lesions which } \\
\text { enhance on delayed postcontrast scans } \\
\text { ("prominent portal triads"); hypodense nodules } \\
<2 \mathrm{~cm} \text { (liver/spleen); hepatosplenomegaly }\end{array}$ & $\begin{array}{l}\text { Other organs involved: } \\
\text { - Skin } \\
\text { - Chest } \\
\text { - GI tract } \\
\text { - Lymph nodes } \\
\text { - Pancreas } \\
\text { - CVS } \\
\text { - GU tract (kidneys) }\end{array}$ & $\begin{array}{l}\text { - Mycobacterium } \\
\text { tuberculosis } \\
\cdot \text { MAC } \\
\text { - Bacillary angiom- } \\
\text { atosis } \\
\text { - P. carinii } \\
\text { - Fungal infections } \\
\text { - AIDS-related lym- } \\
\text { phoma } \\
\text { - Metastatic disease } \\
\text { - Hemangiomas }\end{array}$ \\
\hline
\end{tabular}




\begin{tabular}{|c|c|c|c|c|}
\hline $\begin{array}{l}\text { Organism/ } \\
\text { disease }\end{array}$ & $\begin{array}{l}\text { Organ } \\
\text { involved }\end{array}$ & Radiologic abnormality & Extent of disease & $\begin{array}{l}\text { Differential } \\
\text { diagnosis }\end{array}$ \\
\hline $\begin{array}{l}\text { AIDS-related } \\
\text { lymphoma }\end{array}$ & $\begin{array}{l}\text { Liver/ } \\
\text { spleen/ } \\
\text { bile duct/ } \\
\text { gallbladder }\end{array}$ & $\begin{array}{l}\text { Three patterns: } \\
\text { 1. Large infiltrating masses: } \\
\text { US: hypoechoic, homogeneous } \\
\text { CT: hypodense with homogeneous attenuation } \\
\text { 2. Multiple focal nodules: } \\
\text { US: hypoechoic } \\
\text { CT: low density; variable size, } 1-5 \mathrm{~cm} \text { or larger } \\
\text { 3. Diffuse infiltrating "peritoneal lympho- } \\
\text { matosis": } \\
\text { US: hypoechoic } \\
\text { CT: hypodense; mimics fluid, also with ascites } \\
\text { In all } 3 \text { patterns: } \\
\text { Extensive retroperitoneal and/or mesenteric } \\
\text { lymphadenopathy } \\
\text { CT: soft tissue density with low central attenua- } \\
\text { tion due to central necrosis }\end{array}$ & $\begin{array}{l}\text { Other organs involved: } \\
\text { - Respiratory tract } \\
\cdot \text { CNS } \\
\text { - Retroperitoneum } \\
\text { (pancreas) } \\
\cdot \text { CVS } \\
\text { - Luminal GI tract }\end{array}$ & $\begin{array}{l}\text { - Mycobacterium } \\
\text { tuberculosis } \\
\text { - MAC } \\
\text { - Bacillary } \\
\text { angiomatosis } \\
\text { - P. carinii } \\
\text { - Fungal infections } \\
\text { - Kaposi's sarcoma } \\
\text { - Smooth muscle } \\
\text { tumor }\end{array}$ \\
\hline
\end{tabular}

PCP, Pneumocystis carinii pneumonia; CVS, cardiovascular system; MAC, Mycobacterium avium-intracellulare complex

\subsection{Retroperitoneum}

\begin{tabular}{|c|c|c|c|c|}
\hline $\begin{array}{l}\text { Myco- } \\
\text { bacterium } \\
\text { tuberculosis }\end{array}$ & $\begin{array}{l}\text { Pancreas/ } \\
\text { adrenals }\end{array}$ & $\begin{array}{l}\text { CT: } \\
\text { Nonspecific mass lesions: low-attenuation } \\
\text { nodules; diffuse enlargement; retroperitoneal } \\
\text { lymphadenopathy with central or diffuse low } \\
\text { attenuation; peripancreatic/small bowel } \\
\text { mesenteric, retroperitoneal/pelvic sidewalls; } \\
\text { Fulminant necrotizing pancreatitis in patient } \\
\text { receiving therapy with ddI }\end{array}$ & $\begin{array}{l}\text { - Pancreatic lymph } \\
\text { nodes } \\
\text { - Liver/spleen }\end{array}$ & $\begin{array}{l}\text { Other myco- } \\
\text { bacterial infections }\end{array}$ \\
\hline $\begin{array}{l}\text { Myco- } \\
\text { bacterium } \\
\text { avium-intra- } \\
\text { cellulare } \\
\text { complex }\end{array}$ & Kidneys & $\begin{array}{l}\text { CT: } \\
\text { Hepatosplenomegaly; diffuse jejunal wall } \\
\text { thickening; soft tissue density homogeneous } \\
\text { lymph nodes; mesangial proliferative } \\
\text { glomeronephritis }\end{array}$ & $\begin{array}{l}\text { Other organs involved: } \\
\text { - Lymph nodes } \\
\text { - Bone marrow } \\
\text { - GI tract } \\
\text { - Respiratory tract } \\
\text { - Retroperitoneum } \\
\text { - CNS } \\
\text { - Skin } \\
\text { - CVS }\end{array}$ & $\begin{array}{l}\text { - P. carinii (extra- } \\
\text { pulmonary) } \\
\text { - Mycobacterium } \\
\text { tuberculosis } \\
\text { - Fungal infections } \\
\text { - Kaposi's sarcoma } \\
\text { - AIDS-related } \\
\text { lymphoma }\end{array}$ \\
\hline $\begin{array}{l}\text { AIDS-related } \\
\text { lymphoma }\end{array}$ & $\begin{array}{l}\text { Pancreas/ } \\
\text { adrenals }\end{array}$ & $\begin{array}{l}\text { US: } \\
\text { Hypoechoic masses; lymphadenopathy } \\
\text { CT: } \\
\text { Lymphomatous low-attenuation masses; nodal } \\
\text { disease; distortion of pancreatic duct; obstruc- } \\
\text { tion of CBD; hydronephrosis due to retroperi- } \\
\text { toneal obstructing lymphadenopathy; bulky } \\
\text { conglomerate masses }>5 \mathrm{~cm} \text {; density is close to } \\
\text { skeletal muscle without enhancement } \\
\text { Ga-67 citrate is useful in identifying nodes as } \\
\text { ARL lymph nodes }\end{array}$ & Disseminated disease & Kaposi's sarcoma \\
\hline
\end{tabular}




\begin{tabular}{|c|c|c|c|c|}
\hline $\begin{array}{l}\text { Organism/ } \\
\text { disease }\end{array}$ & $\begin{array}{l}\text { Organ } \\
\text { involved }\end{array}$ & Radiologic abnormality & Extent of disease & $\begin{array}{l}\text { Differential } \\
\text { diagnosis }\end{array}$ \\
\hline $\begin{array}{l}\text { Kaposi's } \\
\text { sarcoma }\end{array}$ & $\begin{array}{l}\text { Pancreas/ } \\
\text { kidneys }\end{array}$ & $\begin{array}{l}\text { CT: } \\
\text { Focal pancreatic/kidney mass; retroperitoneal } \\
\text { lymphadenopathy }(2-3 \mathrm{~cm}) \text {; "streaky" soft tissue } \\
\text { attenuation; infiltrations in the inguinal fat; KS } \\
\text { nodes have a distinctive appearance on dynamic } \\
\text { CT; brightly enhanced nodes on contrast CT }\end{array}$ & $\begin{array}{l}\text { Associated with } \\
\text { lymphadenopathy/skin } \\
\text { manifestations }\end{array}$ & $\begin{array}{l}\text { AIDS-related } \\
\text { lymphoma }\end{array}$ \\
\hline $\begin{array}{l}\text { Aspergillus } \\
\text { fumigatus }\end{array}$ & Kidneys & CT: abscesses & Uni/bilateral & - \\
\hline $\begin{array}{l}\text { Extra- } \\
\text { pulmonary } \\
\text { P. carinii }\end{array}$ & Kidneys & $\begin{array}{l}\text { Renal cortical calcification: } \\
\text { US: diffuse echogenic foci without shadowing; } \\
\text { hepatosplenic involvement } \\
\text { CT: diffuse punctate calcifications involving a } \\
\text { variety of retroperitoneal structures; low-attenu- } \\
\text { ation lesions } \\
\text { AIDS nephropathy: focal segmental glomerulo- } \\
\text { sclerosis } \\
\text { US: increased cortical echogenicity with variable } \\
\text { renal enlargement } \\
\text { CT: hyperdense medulla; enlarged kidneys }\end{array}$ & $\begin{array}{l}\text { Diffuse } \\
\text { Other organs involved: } \\
\text { - Adrenals } \\
\text { - Liver/spleen } \\
\text { - Lymph nodes }\end{array}$ & - \\
\hline $\begin{array}{l}\text { Cytomegalo- } \\
\text { virus }\end{array}$ & $\begin{array}{l}\text { Kidneys/ } \\
\text { adrenals }\end{array}$ & $\begin{array}{l}\text { Focal and segmental glomerulosclerosis; adrenal } \\
\text { stromal tumors (leiomyoma, leiomyosarcoma) }\end{array}$ & - & - \\
\hline $\begin{array}{l}\text { Blastomyco- } \\
\text { sis/histoplas- } \\
\text { mosis }\end{array}$ & $\begin{array}{l}\text { Adrenals/ } \\
\text { kidneys }\end{array}$ & Acute postinfection glomerulonephritis & - & - \\
\hline $\begin{array}{l}\text { Bacillary an- } \\
\text { giomatosis } \\
\text { (Bartonella } \\
\text { henselae) }\end{array}$ & $\begin{array}{l}\text { Retro- } \\
\text { peritoneum }\end{array}$ & $\begin{array}{l}\text { US: high flow on Doppler studies } \\
\text { CT: retroperitoneal lymphadenopathy }\end{array}$ & $\begin{array}{l}\text { Other organs involved: } \\
\text { - Skin } \\
\text { - Mediastinum } \\
\text { - Abdomen } \\
\text { - Skeletal system } \\
\text { - Lymph nodes }\end{array}$ & Kaposi's sarcoma \\
\hline $\begin{array}{l}\text { Candida } \\
\text { albicans }\end{array}$ & Kidneys & $\begin{array}{l}\text { Focal renal lesions (membranoproliferative } \\
\text { glomerulonephritis) }\end{array}$ & Liver/spleen & - \\
\hline
\end{tabular}




\section{Organism/ \\ disease \\ 18.8 Musculoskeletal System}

\begin{tabular}{|c|c|c|c|c|}
\hline Cellulitis & Skin & $\begin{array}{l}\text { Conventional radiology: } \\
\text { Cannot distinguish soft tissue/fascial layers; early } \\
\text { osseous changes cannot be detected } \\
\text { CT: } \\
\text { Increase in density of subcutaneous adipose } \\
\text { tissue ( } 90-120 \mathrm{HU}) \\
\text { MR: } \\
\text { Decrease in signal intensity of fat on T1WI; } \\
\text { increased signal intensity on T2WI, T2 gradient } \\
\text { echo and STIR-imaging }\end{array}$ & $\begin{array}{l}\text { May spread to involve } \\
\text { contiguous structures } \\
\text { and lead to (pyo) myosi- } \\
\text { tis, fasciitis, vascular } \\
\text { thrombosis, and } \\
\text { lymphedema }\end{array}$ & - \\
\hline $\begin{array}{l}\text { Lymphedema } \\
\text { (Strepto- } \\
\text { coccus/ } \\
\text { secondary } \\
\text { infections) }\end{array}$ & $\begin{array}{l}\text { Subcuta- } \\
\text { neous layers }\end{array}$ & $\begin{array}{l}\text { CT: } \\
\text { Subcutaneous reticular or "honeycomb" pattern } \\
\text { fibrous septa: low-attenuation ( } 20-30 \mathrm{HU}) \\
\text { MR: } \\
\text { T1WI: skin thickening; expansion of subcutane- } \\
\text { ous tissue with a characteristic "honeycomb" } \\
\text { pattern of low signal intensity streaks } \\
\text { STIR: } \\
\text { Serpiginous increased signal intensity in subcu- } \\
\text { taneous fat }\end{array}$ & - & - \\
\hline $\begin{array}{l}\text { Dermatologic } \\
\text { disorders } \\
\text { (Helicobacter } \\
\text { cinaedi, } \\
\text { Streptococcus } \\
\text { pneumoniae, } \\
\text { secondary } \\
\text { infections) }\end{array}$ & Skin & $\begin{array}{l}\text { Eosinophilic folliculitis; pruritic papules; } \\
\text { bacillary angiomatosis; paraneoplastic } \\
\text { pemphigus }\end{array}$ & - & Kaposi's sarcoma \\
\hline $\begin{array}{l}\text { Tenosynovitis } \\
\text { (candida } \\
\text { albicans) }\end{array}$ & $\begin{array}{l}\text { Tendons } \\
\text { sheath }\end{array}$ & $\begin{array}{l}\text { US/CT: } \\
\text { edema of tendon sheat; tenosynoritis }\end{array}$ & - & - \\
\hline Septic bursitis & Bursa & $\begin{array}{l}\text { US/CT: } \\
\text { edema of bursa; bursitis }\end{array}$ & $\begin{array}{l}\text { - Olecranon } \\
\text { - Prepatellar } \\
\text { - Subdeltoid region }\end{array}$ & $\begin{array}{l}\text { - Staphylococcus } \\
\text { aureus } \\
\text { - Streptococcus } \\
\text { pneumoniae } \\
\text { - Mycobacterium } \\
\text { marinum } \\
\text { - Sporothrix } \\
\text { schenkii }\end{array}$ \\
\hline Myopathy & $\begin{array}{l}\text { Muscular } \\
\text { system }\end{array}$ & $\begin{array}{l}C T / M R \text { : } \\
\text { Myonecrotic muscle: enlarged, decreased attenu- } \\
\text { ation; localized intramuscular collection of fluid } \\
\text { or gas may be seen; contrast } C T / M R \text { may differen- } \\
\text { tiate between normal and myonecrotic tissue }\end{array}$ & Localized/diffuse & $\begin{array}{l}\text { - Bacterial infec- } \\
\text { tions (Staphylo- } \\
\text { coccus aureus) } \\
\text { - Fungal infections } \\
\text { - Parasitic infec- } \\
\text { tions }\end{array}$ \\
\hline
\end{tabular}




\begin{tabular}{|c|c|c|c|c|}
\hline $\begin{array}{l}\text { Organism/ } \\
\text { disease }\end{array}$ & $\begin{array}{l}\text { Organ } \\
\text { involved }\end{array}$ & Radiologic abnormality & Extent of disease & $\begin{array}{l}\text { Differential } \\
\text { diagnosis }\end{array}$ \\
\hline Osteomyelitis & $\begin{array}{l}\text { Skeletal } \\
\text { system }\end{array}$ & $\begin{array}{l}\text { Conventional radiography } \\
\text { - Periosteal reaction } \\
\text { - Soft tissue swelling } \\
\text { - Cortical erosions } \\
\text { As infection progresses: osteolytic + osteo- } \\
\text { sclerotic changes } \\
\text { Bone scintigraphy/MR are helpful for early detec- } \\
\text { tion of osseous involvement and to demonstrate } \\
\text { the extent of bone marrow infection }\end{array}$ & Localized & $\begin{array}{l}\text { - Staphylococcus } \\
\text { aureus } \\
\text { - Nocardia } \\
\text { asteroides } \\
\text { - Salmonella } \\
\text { typhimurium } \\
\text { - Gonococcus } \\
\text { - CMV } \\
\text { - Candida albicans } \\
\text { - Aspergillus } \\
\text { fumigatus } \\
\text { - Toxoplasma gondii } \\
\text { - Spiromycosis }\end{array}$ \\
\hline $\begin{array}{l}\text { Bacillary } \\
\text { angiomatosis } \\
\text { (Bartonella } \\
\text { henselae, } \\
\text { Bartonella } \\
\text { quintana) }\end{array}$ & Skin & $\begin{array}{l}\text { Angiomatous cutaneous lesions } \\
\text { Conventional radiography: } \\
\text { Osteolytic lesions with overlying soft tissue mass: } \\
\text { periostitis } \\
\text { Tc-99m scintigraphy: } \\
\text { Increased uptake } \\
\text { CT/MR: } \\
\text { Intense contrast enhancement of soft tissue } \\
\text { lesions }\end{array}$ & $\begin{array}{l}\text { - Liver/spleen } \\
\text { - Lymph nodes } \\
\text { - Respiratory tract } \\
\text { - Skeletal system } \\
\text { - Skin } \\
\text { - Conjunctivae }\end{array}$ & - \\
\hline $\begin{array}{l}\text { Tuberculosis } \\
\text { (Myco- } \\
\text { bacterium } \\
\text { tuberculosis; } \\
\text { Myco- } \\
\text { bacterium } \\
\text { avium-intra- } \\
\text { cellulare) }\end{array}$ & $\begin{array}{l}\text { Skeletal } \\
\text { system }\end{array}$ & $\begin{array}{l}\text { Tuberculous osteomyelitis: } \\
\text { vertebral column/cervical spine } \\
\text { - Focal osteolysis with varying amounts of ebur- } \\
\text { nation and periostitis } \\
\text { - Sequestrum formation } \\
\text { Tuberculous spondylitis of thoracic/lumbar } \\
\text { spines } \\
\text { Conventional radiography: } \\
\text { Osteonecrosis; bone destruction involving the } \\
\text { anterior vertebral body, narrowing of adjacent } \\
\text { intervertebral disc; similar bone destruction of } \\
\text { the contiguous vertebral body; progressive } \\
\text { vertebral collapse with anterior wedging } \\
\text { ("gibbus deformity") } \\
\text { US/CT: } \\
\text { Psoas/paraspinal abscess } \\
\text { Contrast MR: } \\
\text { Vertebral intraosseous abscess; meningeal } \\
\text { involvement; subligamentous spread; paraspinal } \\
\text { abscess }\end{array}$ & $\begin{array}{l}\text { Other organs involved: } \\
\text { - Respiratory tract } \\
\text { - Metaphyseal involve- } \\
\text { ment of bones: hips/ } \\
\text { knee } \\
\text { - Sacral bones }\end{array}$ & $\begin{array}{l}\text { Staphylococcus } \\
\text { aureus }\end{array}$ \\
\hline
\end{tabular}




\begin{tabular}{|c|c|c|c|c|}
\hline $\begin{array}{l}\text { Organism/ } \\
\text { disease }\end{array}$ & $\begin{array}{l}\text { Organ } \\
\text { involved }\end{array}$ & Radiologic abnormality & Extent of disease & $\begin{array}{l}\text { Differential } \\
\text { diagnosis }\end{array}$ \\
\hline $\begin{array}{l}\text { Atypical } \\
\text { mycobacteri- } \\
\text { al infection } \\
\text { (Mycobacteri- } \\
\text { um avium- } \\
\text { intracellulare } \\
\text { complex) }\end{array}$ & $\begin{array}{l}\text { Meta/dia- } \\
\text { physes of } \\
\text { long bones }\end{array}$ & $\begin{array}{l}\text { Conventional radiography: } \\
\text { - Discrete osteolytic lesions which have sclerotic } \\
\text { margins (osteomyelitis) } \\
\text { - Osteoporosis } \\
\text { - Abscesses/sinus tracts/sarcoma }\end{array}$ & $\begin{array}{l}\text { Multiple rather than } \\
\text { solitary } \\
\text { Other organs involved: } \\
\text { - Bone marrow } \\
\text { - Lymph nodes } \\
\text { - Respiratory tract } \\
\text { - GI tract } \\
\text { - Liver/spleen } \\
\text { - GU tract } \\
\text { - Blood } \\
\text { - Skin }\end{array}$ & $\begin{array}{l}\text { - Tuberculosis } \\
\text { - Extrapulmonary } \\
\text { P. carinii } \\
\text { - Fungal infections } \\
\text { - Kaposi's sarcoma } \\
\text { - AIDS-related lym- } \\
\text { phoma }\end{array}$ \\
\hline $\begin{array}{l}\text { Myco- } \\
\text { bacterium } \\
\text { haemophilum }\end{array}$ & $\begin{array}{l}\text { Tendon } \\
\text { sheats }\end{array}$ & Tenosynovitis & $\begin{array}{l}\text { - Knee } \\
\text { - Ankle } \\
\text { - Hip } \\
\text { - Digits }\end{array}$ & - \\
\hline Arthritis & $\begin{array}{l}\text { Synovial } \\
\text { joints }\end{array}$ & $\begin{array}{l}\text { - Spondyloarthropathic arthritis (Reiter's } \\
\text { syndrome) } \\
\text { - HIV-associated arthritis; painful articular } \\
\text { syndrome } \\
\text { - Acute symmetric polyarthritis } \\
\text { - Septic arthritis: common features, difficult to } \\
\text { differentiate from each other } \\
\text { - Tuberculous arthritis may affect large joints: } \\
\text { monoarticular } \\
\text { Conventional radiography: } \\
\text { Phemister's triad: } \\
\text { - Juxtra-articular osteoporosis } \\
\text { - Peripherally located osseous erosions } \\
\text { - Gradual narrowing of interosseous space }\end{array}$ & $\begin{array}{l}\text { - Foot } \\
\text { - Ankle } \\
\text { - Knee } \\
\text { - Hip } \\
\text { - Multidigital dactylitis } \\
\text { - Ankle } \\
\text { - Shoulder }\end{array}$ & $\begin{array}{l}\text { - Enteric pathogens } \\
\text { - Staphyloccoccus } \\
\text { aureus } \\
\text { - Candida albicans } \\
\text { - Streptococcus } \\
\text { pneumoniae } \\
\text { - MAC } \\
\text { - M. kansasii } \\
\text { - Mycobacterium } \\
\text { haemophilum }\end{array}$ \\
\hline $\begin{array}{l}\text { Avascular } \\
\text { necrosis }\end{array}$ & $\begin{array}{l}\text { Skeletal } \\
\text { system }\end{array}$ & $\begin{array}{l}\text { Conventional radiography: } \\
\text { Subchondral fracture; sclerosis with crescentic } \\
\text { radiolucency; flattening of epiphyseal head; } \\
\text { widening of epiphyseal line; rarefaction of } \\
\text { metaphysis; preservation of joint space } \\
\text { MR: } \\
\text { Low signal intensity band or rings of involved } \\
\text { bone } \\
\text { T2WI: "double line" sign of adjacent low/high } \\
\text { signal intensity }\end{array}$ & Local & - \\
\hline $\begin{array}{l}\text { Hypertrophic } \\
\text { pulmonary } \\
\text { osteo- } \\
\text { arthropathy }\end{array}$ & $\begin{array}{l}\text { Skeletal } \\
\text { system }\end{array}$ & $\begin{array}{l}\text { Conventional radiography: } \\
\text { Subperiosteal new bone formation; soft tissue } \\
\text { thickening; joint effusion; clubbing of digits } \\
\text { Bone scintigraphy: } \\
\text { Increased uptake at areas of new bone formation }\end{array}$ & Local & - \\
\hline
\end{tabular}




\begin{tabular}{|c|c|c|c|c|}
\hline $\begin{array}{l}\text { Organism/ } \\
\text { disease }\end{array}$ & $\begin{array}{l}\text { Organ } \\
\text { involved }\end{array}$ & Radiologic abnormality & Extent of disease & $\begin{array}{l}\text { Differential } \\
\text { diagnosis }\end{array}$ \\
\hline Spondylitis & $\begin{array}{l}\text { Interverte- } \\
\text { bral (disc) } \\
\text { space }\end{array}$ & $\begin{array}{l}\text { Conventional radiography: } \\
\text { Bony erosions of adjacent end-plates } \\
\text { Narrowing of disc space } \\
\text { MR: } \\
\text { T1WI: decreased signal intensity of the discs } \\
\text { T2WI: increasing signal intensity; paraspinal/ } \\
\text { epidural inflammation; edema, abscess } \\
\text { formation with contrast ehancement; vertebral } \\
\text { end-plates are also affected }\end{array}$ & Localized & $\begin{array}{l}\text { - Staphylococcus } \\
\text { aureus } \\
\text { - Cryptococcus } \\
\text { neoformans } \\
\text { - Candida albicans } \\
\text { - Candida tropicalis } \\
\text { - Pseudomonas } \\
\text { aeruginosa }\end{array}$ \\
\hline $\begin{array}{l}\text { Kaposi's } \\
\text { sarcoma (KS) }\end{array}$ & $\begin{array}{l}\text { Musculo } \\
\text { skeletal } \\
\text { system }\end{array}$ & $\begin{array}{l}\text { Plain radiographs may be negative } \\
\text { Scintigraphy may be negative } \\
\text { CT: } \\
\text { Multiple osteolytic lesions in pelvis, hips, spine, } \\
\text { ribs, associated with periosteal reaction and } \\
\text { overlying soft tissue mass } \\
\text { MR: } \\
\text { Extensive edema and subcuteneous tissue chang- } \\
\text { es with minimal muscle involvement; extensive } \\
\text { muscle involvement with adjacent subcutaneous } \\
\text { lesions }\end{array}$ & $\begin{array}{l}\text { Multifocal involvement } \\
\text { Other organs involved: } \\
\text { - Mucocutaneous } \\
\text { - Sternum } \\
\text { - Ribs } \\
\text { - Thoracic spine } \\
\text { - GI tract } \\
\text { - Liver/spleen } \\
\text { - Lymph nodes }\end{array}$ & $\begin{array}{l}\text { - Bacillary angiom- } \\
\text { atosis } \\
\text { - Tuberculosis } \\
\text { - AIDS-related lym- } \\
\text { phoma }\end{array}$ \\
\hline $\begin{array}{l}\text { AIDS-related } \\
\text { lymphoma }\end{array}$ & $\begin{array}{l}\text { Musculo- } \\
\text { skeletal } \\
\text { system }\end{array}$ & $\begin{array}{l}\text { Conventional radiography/CT: } \\
\text { Permeative osteolytic lesions with cortical } \\
\text { destruction; sclerosis and indistinct transition } \\
\text { zone; periosteal reaction; pathologic fractures } \\
\text { and associated soft tissue mass } \\
\text { MR: } \\
\text { T2WI: hyperintense signal mass }\end{array}$ & $\begin{array}{l}\text { - Lower extremities } \\
\text { - Skull } \\
\text { - Pelvis } \\
\text { - Spine } \\
\text { - GI tract } \\
\text { - CNS }\end{array}$ & $\begin{array}{l}\text { Kaposi's } \\
\text { sarcoma }\end{array}$ \\
\hline
\end{tabular}

CMV, Cytomegalovirus; MAC, Mycobacterium avium-intracellulare complex STIR; short tau inversion recovery

\subsection{Different Radiologic Patterns on Chest Radiographs in AIDS}

\begin{tabular}{lll}
\hline Observations & Incidence & Differential Diagnosis \\
\hline $\begin{array}{l}\text { Bronchial or bronchiolar } \\
\text { wall } \\
\text { thickening }\end{array}$ & Common & $\begin{array}{l}\text { Pyogenic infections } \\
\text { Mycobacterial infections (MTb, MAC) } \\
\text { Kaposi's sarcoma }\end{array}$ \\
\cline { 2 - 2 } & Uncommon/absent & $\begin{array}{l}\text { ARL } \\
\text { Viral infections } \\
\text { Fungal infections } \\
\text { LIP, PCP }\end{array}$ \\
& \\
& \\
& \\
\end{tabular}




\begin{tabular}{|c|c|c|}
\hline Observations & Incidence & Differential Diagnosis \\
\hline Bronchiectasis & $\begin{array}{l}\text { Common } \\
\text { Uncommon/absent }\end{array}$ & $\begin{array}{l}\text { Mycobacterial infections (MTb, MAC) } \\
\text { Pyogenic infections } \\
\text { Fungal infections, PCP } \\
\text { Kaposi's sarcoma } \\
\text { ARL } \\
\text { Viral infections } \\
\text { LIP }\end{array}$ \\
\hline Endoluminal polyp/mass & $\begin{array}{l}\text { Uncommon } \\
\text { Absent }\end{array}$ & $\begin{array}{l}\text { Mycobacterial infections (MTb, MAC) } \\
\text { Fungal infections } \\
\text { Kaposi's sarcoma } \\
\text { ARL (rare) } \\
\text { Pyogenic infections, } \\
\text { PCP, viral infections } \\
\text { LIP }\end{array}$ \\
\hline $\begin{array}{l}\text { Intrathoracic (mediasti- } \\
\text { nal/hilar) } \\
\text { lymph- } \\
\text { adenopathy }\end{array}$ & $\begin{array}{l}\text { Common } \\
\text { Uncommon/absent }\end{array}$ & $\begin{array}{l}\text { Mycobacterial infections (MTb, MAC) } \\
\text { Fungal infections } \\
\text { ARL } \\
\text { Kaposi's sarcoma } \\
\text { PCP } \\
\text { Viral infections } \\
\text { Bacterial infections }\end{array}$ \\
\hline $\begin{array}{l}\text { Pleural } \\
\text { effusions } \\
\text { (isolated) }\end{array}$ & $\begin{array}{l}\text { Common } \\
\text { Uncommon/absent }\end{array}$ & $\begin{array}{l}\text { Kaposi's sarcoma } \\
\text { ARL } \\
\text { Bacterial infections } \\
\text { PCP } \\
\text { Viral infections } \\
\text { Mycobacterial infections (MTb, MAC) } \\
\text { Fungal infections } \\
\text { LIP }\end{array}$ \\
\hline Thick-walled cavities & Uncommon/absent & $\begin{array}{l}\text { Fungal infections (Aspergillus, cryptococcus) } \\
\text { Mycobacterial infections (MTb, depending on CD4 cell count, } \\
\text { MAC) } \\
\text { Rhodococcus } \\
\text { Septic emboli } \\
\text { PCP } \\
\text { Viral infections } \\
\text { Kaposi's sarcma } \\
\text { LIP } \\
\text { ARL }\end{array}$ \\
\hline Thin-walled cavities & Common & PCP \\
\hline
\end{tabular}




\section{Observations}

\section{Incidence}

Common

Solitary

(paren-

chymal)

nodules
Differential Diagnosis

Kaposi's sarcoma (peribronchovascular and subpleural)

ARL

Fungal infections (Aspergillus, cryptococcus)

Nocardia

Myobacterial infections (MTb, MAC)

Septic emboli

Bronchogenic carcinoma

Uncommon

CMV

\begin{tabular}{|c|c|c|}
\hline $\begin{array}{l}\text { Multiple } \\
\text { (miliary) } \\
\text { nodules }\end{array}$ & Uncommon & $\begin{array}{l}\text { PCP } \\
\text { CMV } \\
\text { Tuberculosis } \\
\text { Fungal infections } \\
\text { PCP }\end{array}$ \\
\hline \multirow{2}{*}{$\begin{array}{l}\text { Homo- } \\
\text { geneous } \\
\text { consolidation }\end{array}$} & Common & $\begin{array}{l}\text { Bacterial infections } \\
\text { Fungal infections }\end{array}$ \\
\hline & Uncommon/absent & $\begin{array}{l}\text { Mycobacterial infections (MTb, MAC) } \\
\text { PCP } \\
\text { Viral } \\
\text { Kaposi's sarcoma } \\
\text { ARL }\end{array}$ \\
\hline $\begin{array}{l}\text { Ground-glass attenuation } \\
\text { (CT) }\end{array}$ & Common & $\begin{array}{l}\text { PCP } \\
\text { Pyogenic infections } \\
\text { Viral infections (CMV) } \\
\text { Kaposi's sarcoma } \\
\text { Bacterial infections } \\
\text { LIP }\end{array}$ \\
\hline $\begin{array}{l}\text { Reticular/reticulo- } \\
\text { nodular } \\
\text { pattern }\end{array}$ & Common & $\begin{array}{l}\text { PCP } \\
\text { Viral infections (CMV) } \\
\text { Kaposi's sarcoma (coarse) } \\
\text { ARL } \\
\text { LIP }\end{array}$ \\
\hline Ascites & Uncommon & $\begin{array}{l}\text { P. carinii (extrapulmonary) } \\
\text { ARL } \\
\text { Mycobacterium tuberculosis } \\
\text { Atypical mycobacterium } \\
\text { Kaposi's sarcoma } \\
\text { Bacillary angiomatosis }\end{array}$ \\
\hline
\end{tabular}

MTb, Mycobacterium tuberculosis; MAC, Maycobacterium avium-intracellulare complex; ARL, AIDS-related lymphoma; LIP, lymphocytic interstitial pneumonia; PCP, Pneumocystis carinii pneumonia; CMV, cytomegalovirus 


\subsection{Pathogens and Neoplasms in AIDS: Cytologic Methods}

This table is adapted (and modified) from CHAN NH (1998) AIDS imaging; a practical clinical approach, Chap 6. SAUNDERS, London

\section{Viral infections}

\begin{tabular}{|c|c|c|c|c|}
\hline Cytomegalovirus & $\begin{array}{l}\text { Adrenals } \\
\text { Respiratory tract } \\
\text { GI tract } \\
\text { CNS } \\
\text { Retina }\end{array}$ & $\begin{array}{l}\text { Bronchoalveolar lavage } \\
\text { Smears } \\
\text { FNA biopsies } \\
\text { Transbronchial biopsies } \\
\text { Open lung biopsies }\end{array}$ & $\begin{array}{l}\text { PAP, H\&E, Giemsa stain } \\
\text { Monoclonal antibodies for } \\
\text { immunochemistry } \\
\text { In situ hybridization }\end{array}$ & $\begin{array}{l}\text { Endothelial cells or histiocytic } \\
\text { clusters; Enlarged large viola- } \\
\text { ceous to dark red intranuclear } \\
\text { inclusion bodies, surrounded } \\
\text { by thin halo }\end{array}$ \\
\hline $\begin{array}{l}\text { Herpes simplex } \\
\text { virus (HSV-1, } \\
\text { HSV-2) } \\
\text { Herpes zoster } \\
\text { virus }\end{array}$ & $\begin{array}{l}\text { Mucocutaneous } \\
\text { Perianal region } \\
\text { Oropharyngeal } \\
\text { region } \\
\text { Esophageal } \\
\text { region }\end{array}$ & $\begin{array}{l}\text { Sputum } \\
\text { Bronchial brushing/ } \\
\text { washing (BAL) } \\
\text { Smears from skin, oral } \\
\text { mucosa, esophagus and } \\
\text { remaining GI tract } \\
\text { FNA biopsies }\end{array}$ & $\begin{array}{l}\text { PAP, H\&E, Giemsa stain } \\
\text { Monoclonal antibodies for } \\
\text { immunochemistry } \\
\text { In situ hybridization }\end{array}$ & $\begin{array}{l}\text { Vesicles/ulcerations: small } \\
\text { esophilic, intranuclear, inclu- } \\
\text { sion bodies }\end{array}$ \\
\hline
\end{tabular}

\section{Bacterial infections}

\begin{tabular}{|c|c|c|c|c|}
\hline $\begin{array}{l}\text { Mycobacterium } \\
\text { tuberculosis } \\
\text { Mycobacterium } \\
\text { avium-intra- } \\
\text { cellulare complex }\end{array}$ & $\begin{array}{l}\text { Lymph nodes } \\
\text { Liver/spleen } \\
\text { Bone marrow } \\
\text { GI tract } \\
\text { Respiratory tract } \\
\text { CNS (rare) } \\
\text { Skin (rare) } \\
\text { CVS (rare) }\end{array}$ & $\begin{array}{l}\text { Smears } \\
\text { FNA specimen of the } \\
\text { lymph nodes or other } \\
\text { mass lesions } \\
\text { Bone marrow biopsy/aspi- } \\
\text { ration } \\
\text { Bronchoscopy specimen } \\
\text { Endoscopic biopsy }\end{array}$ & $\begin{array}{l}\text { H\&E stain } \\
\text { Ziehl-Neelsen stain } \\
\text { Kinynon stain } \\
\text { Rhodamine-auramine } \\
\quad \text { stain } \\
\text { DNA probes } \\
\text { PAS/GMS/Giemsa stain } \\
\text { Metaminamine stain } \\
\text { Diff Quik }\end{array}$ & $\begin{array}{l}\text { Multiple noncaseating granu- } \\
\text { lomas within lobular paren- } \\
\text { chyma and portal tracts of the } \\
\text { liver; acid fast microorgan- } \\
\text { isms in cytoplasm of mac- } \\
\text { rophages; single cells, small } \\
\text { clusters, or large groups of } \\
\text { histiocytes that are filled with } \\
\text { small rods; inflammatory in- } \\
\text { filtrates usually absent }\end{array}$ \\
\hline $\begin{array}{l}\text { Pneumocystis } \\
\text { carinii }\end{array}$ & $\begin{array}{l}\text { Respiratory tract } \\
\text { Liver/spleen } \\
\text { GU tract }\end{array}$ & $\begin{array}{l}\text { Induction and collection } \\
\text { of sputum } \\
\text { FNA biopsy of mass } \\
\text { lesions for extra- } \\
\text { pulmonary disease } \\
\text { Bronchial brushing/ } \\
\text { washing } \\
\text { BAL via fiberoptic } \\
\text { bronchoscopy } \\
\text { FNA biopsy } \\
\text { Sputum } \\
\text { Smears }\end{array}$ & $\begin{array}{l}\text { PAP stain: specific } \\
\text { H\&E stain: specific } \\
\text { GMS stain } \\
\text { Giemsa or toluidine blue } \\
\text { stain } \\
\text { Autofluorescence } \\
\text { Methylene blue stain }\end{array}$ & $\begin{array}{l}\text { Acellular, granular foamy } \\
\text { alveolar casts }\end{array}$ \\
\hline
\end{tabular}




\section{Parasitic infections}

\begin{tabular}{|c|c|c|c|c|}
\hline $\begin{array}{l}\text { Toxoplasma } \\
\text { gondii }\end{array}$ & $\begin{array}{l}\text { CNS } \\
\text { Respiratory tract } \\
\text { Lymph nodes }\end{array}$ & $\begin{array}{l}\text { Open biopsy of enlarged } \\
\text { regional lymph nodes } \\
\text { FNA or tissue biopsy of in- } \\
\text { tracranial mass } \\
\text { BAL } \\
\text { Smears }\end{array}$ & $\begin{array}{l}\text { Giemsa stain } \\
\text { H\&E stain } \\
\text { PAP/PAS stain } \\
\text { GMS stain } \\
\text { Monoclonal antibodies } \\
\text { with immunoperoxidase } \\
\text { stain } \\
\text { Cannot be cultured; } \\
\text { morphologic identifica- } \\
\text { tion is crucial }\end{array}$ & $\begin{array}{l}\text { Toxoplasma cysts } \\
\text { three morphologic forms: } \\
\text { - tachyzoites (acute infection: } \\
\text { 3-7 mm } \times 2-4 \text { mm tear drop, } \\
\text { crescent shape; groups or } \\
\text { aggregates within mem- } \\
\text { brane, round cytoplasmic } \\
\text { vacuoles; oval or rounded) } \\
\text { - Bradyzoites (chronic infec- } \\
\text { tion): rounded, packed } \\
\text { tightly into cysts ( } 30-100 \\
\text { mm) } \\
\text { - Oocysts: contain up to eight } \\
\text { sporozoites }\end{array}$ \\
\hline Cryptosporidium & $\begin{array}{l}\text { GI tract } \\
\text { Biliary tract } \\
\text { Respiratory tract }\end{array}$ & - & Ziehl-Neelsen stain & $\begin{array}{l}\text { Acid-fast micro-organisims } \\
(2-6 \mu \mathrm{m})\end{array}$ \\
\hline $\begin{array}{l}\text { Microsporidium/ } \\
\text { Isospora belli }\end{array}$ & $\begin{array}{l}\text { GI tract (small } \\
\text { bowel) } \\
\text { Lymph nodes }\end{array}$ & & & $\begin{array}{l}\text { Electron microscope } \\
\text { examination }\end{array}$ \\
\hline
\end{tabular}

\section{Fungal infections}

\begin{tabular}{|c|c|c|c|c|}
\hline Candida albicans & $\begin{array}{l}\text { Skin } \\
\text { Oral cavity } \\
\text { Esophagus } \\
\text { Respiratory tract }\end{array}$ & $\begin{array}{l}\text { Endoscopy specimen } \\
\text { Bronchoscopy specimen }\end{array}$ & $\begin{array}{l}\text { PAP/PAS stain } \\
\text { GMS stain } \\
\text { Culture } \\
\text { Tissue immunohistochem- } \\
\text { istry or DNA probes not } \\
\text { necessary }\end{array}$ & $\begin{array}{l}\text { Invading fungi surrounded by } \\
\text { granulocytes; buds and } \\
\text { pseudohyphae without } \\
\text { branching or true septations }\end{array}$ \\
\hline $\begin{array}{l}\text { Histoplasmosis } \\
\text { (Histoplasma } \\
\text { capsulatum) }\end{array}$ & $\begin{array}{l}\text { CNS } \\
\text { Respiratory tract } \\
\text { Liver/spleen } \\
\text { Adrenals } \\
\text { Kidney }\end{array}$ & $\begin{array}{l}\text { FNA biopsy of mass } \\
\text { lesions } \\
\text { BAL } \\
\text { Peripheral blood smears }\end{array}$ & $\begin{array}{l}\text { PAP/PAS stain } \\
\text { Giemsa stain } \\
\text { GMS stain } \\
\text { Bone marrow culture } \\
\text { Tissue immunohisto } \\
\text { chemistry or DNA probe } \\
\text { not necessary }\end{array}$ & - \\
\hline $\begin{array}{l}\text { Cryptococcosis } \\
\text { (Cryptococcus } \\
\text { neoformans) }\end{array}$ & $\begin{array}{l}\text { CNS } \\
\text { Lymph nodes } \\
\text { Liver/spleen } \\
\text { Bone marrow }\end{array}$ & $\begin{array}{l}\text { Lumbar puncture (CSF) } \\
\text { FNA specimen of a mass } \\
\text { lesion } \\
\text { Skin biopsy }\end{array}$ & $\begin{array}{l}\text { PAP stain } \\
\text { PAS stain } \\
\text { GMS or mucicarmine stain } \\
\text { India ink stain (CSF) }\end{array}$ & $\begin{array}{l}\text { Epitheloid, multinucleated } \\
\text { giant cells with organisms in } \\
\text { their cytoplasm; small, some- } \\
\text { times teardrop-shaped bud- } \\
\text { ding yeasts with a diameter of } \\
4-7 \mu \mathrm{m} \text {. } \\
\text { Cells have prominent capsules }\end{array}$ \\
\hline $\begin{array}{l}\text { Coccidioidomy- } \\
\text { cosis }\end{array}$ & $\begin{array}{l}\text { Respiratory tract } \\
\text { CNS }\end{array}$ & $\begin{array}{l}\text { BAL } \\
\text { Transbronchial biopsy }\end{array}$ & $\begin{array}{l}\text { PAP stain } \\
\text { PAS stain } \\
\text { GMS or mucicarmine stain } \\
\text { India ink stain (CSF) }\end{array}$ & \\
\hline
\end{tabular}




\begin{tabular}{|lll} 
Infections & Organ involved Diagnostic method & $\begin{array}{l}\text { Cytogenic staining } \\
\text { Pathologic } \\
\text { characteristics }\end{array}$
\end{tabular}

\section{Neoplasms}

\begin{tabular}{|c|c|c|c|c|}
\hline Kaposi's sarcoma & $\begin{array}{l}\text { Skin } \\
\text { Mucous } \\
\quad \text { membrane } \\
\text { Bronchial tree } \\
\text { Oropharynx } \\
\text { GI tract } \\
\text { Lymph nodes } \\
\text { Liver } \\
\text { CVS } \\
\text { GU tract (kidneys) }\end{array}$ & $\begin{array}{l}\text { Endoscopy } \\
\text { Biopsy }\end{array}$ & $\begin{array}{l}\text { FNA biopsies } \\
\text { Cytology plays no role in } \\
\text { diagnosis }\end{array}$ & $\begin{array}{l}\text { Five patterns are recognized: } \\
\text { early, nodular, aggressive cu- } \\
\text { taneous, lymphadenopathic, } \\
\text { and systemic generalized } \\
\text { Kaposi's sarcoma } \\
\text { Histology: } \\
\text { Early angiomatous spindle } \\
\text { cell, inflammatory, mixed and } \\
\text { pleomorphic variant } \\
\text { Early lesions: } \\
\text { Small red nodules: } \\
1-2 \text { mm, later macular } \\
\text { plaque-like lesions; slight to } \\
\text { moderate cytonuclear pleo- } \\
\text { morphism with mitoses. } \\
\text { Tumor cells show erythroph- } \\
\text { agocytosis, perivascular } \\
\text { growth. } \\
\text { Reactive proliferation of en- } \\
\text { dothelial cells; irregularly di- } \\
\text { lated vascular spaces coated } \\
\text { with swollen endothelial cells, } \\
\text { similar to HHV-8 }\end{array}$ \\
\hline $\begin{array}{l}\text { AIDS-related } \\
\text { lymphoma }\end{array}$ & $\begin{array}{l}\text { Respiratory tract } \\
\text { GI tract } \\
\text { CNS } \\
\text { Pleura } \\
\text { Pericardium } \\
\text { Peritoneal cavity }\end{array}$ & $\begin{array}{l}\text { FNA biopsy of mass } \\
\text { lesions } \\
\text { Smears }\end{array}$ & $\begin{array}{l}\text { H\&E stain } \\
\text { Diff Quik } \\
\text { Ziehl-Neelsen stain } \\
\text { Giemsa stain } \\
\text { Gram stain } \\
\text { AFB }\end{array}$ & $\begin{array}{l}\text { Pleomorphic population of } \\
\text { lymphocytes, plasma cells and } \\
\text { macrophages in a clear back- } \\
\text { ground, without granulomas } \\
\text { or necrosis. } \\
\text { Mixed cellularity. } \\
\text { Histology: } \\
\text { - Centroblastic cells } \\
\text { - Lymphoblastic cells } \\
\text { - Immunoblastic cells }\end{array}$ \\
\hline
\end{tabular}

FNA, Fine-needle aspiration; PAP, Papanicolaou stain; H\&E, hematoxylin and eosin stain; GMS, Grocott's methenamine silver stain; PAS, periodic acid-Schiff stain; CSF, cerebrospinal fluid; AFB, acid-fast bacilli; BAL, bronchoalveolar lavage; CVS, cardiovascular system 